\title{
Amyloid Beta Peptide Is an Endogenous Negative Allosteric Modulator of Leptin Receptor
}

\author{
Erika Cecon $^{a}$ Tori Lhomme ${ }^{b}$ Tangui Maurice ${ }^{c}$ Marine Luka ${ }^{a}$ Min Chen $^{a}$ \\ Anisia Silva $^{a}$ Joris Wauman ${ }^{d}$ Lennart Zabeau $^{d}$ Jan Tavernier ${ }^{d}$ \\ Vincent Prévot $^{\mathrm{b}}$ Julie Dam ${ }^{\mathrm{a}}$ Ralf Jockers ${ }^{\mathrm{a}}$

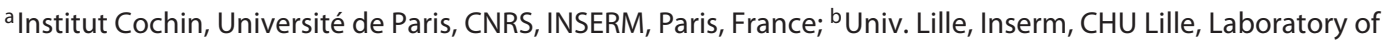 \\ Development and Plasticity of the Neuroendocrine Brain, EGID, DistAlz, Lille Neuroscience \& Cognition, UMR-S \\ 1172, Lille, France; ' ${ }^{C} M M D N$, University of Montpellier, EPHE, INSERM, UMR_S1198, Montpellier, France; ${ }^{d}$ VIB Center \\ for Medical Biotechnology, Department of Biomolecular Medicine, University of Ghent, Ghent, Belgium
}

\section{Keywords}

Alzheimer's disease - Leptin receptor · Amyloid beta .

Metabolism

\begin{abstract}
Introduction: Metabolic dysfunction is now recognized as a pivotal component of Alzheimer's disease (AD), the most common dementia worldwide. However, the precise molecular mechanisms linking metabolic dysfunction to AD remain elusive. Objective: Here, we investigated the direct impact of soluble oligomeric amyloid beta $(A \beta)$ peptides, the main molecular hallmark of $A D$, on the leptin system, a major component of central energy metabolism regulation. Methods: We developed a new time-resolved fluorescence resonance energy transfer-based $A \beta$ binding assay for the leptin receptor (LepR) and studied the effect of $A \beta$ on LepR function in several in vitro assays. The in vivo effect of $A \beta$ on LepR function was studied in an $A \beta$-specific AD mouse model and in pro-opiomelanocortin (POMC) neurons of the hypothalamic arcuate nucleus. Results: We revealed specific and high-affinity $\left(K_{i}=0.1 \mathrm{~nm}\right)$ binding of $A \beta$ to LepR. Pharmacological characterization of this interaction showed that $A \beta$ binds allosterically to the extracellular domain of LepR and
\end{abstract}

karger@karger.com www.karger.com/nen

Karger" negatively affects receptor function. Negative allosteric modulation of LepR by $A \beta$ was detected at the level of signaling pathways (STAT-3, AKT, and ERK) in vitro and in vivo. Importantly, the leptin-induced response of POMC neurons, key players in the regulation of metabolic function, was completely abolished in the presence of $A \beta$. Conclusion: Our data indicate that $A \beta$ is a negative allosteric modulator of LepR, resulting in impaired leptin action, and qualify LepR as a new and direct target of $A \beta$ oligomers. Preventing the interaction of $A \beta$ with LepR might improve both the metabolic and cognitive dysfunctions in AD condition.

(c) 2020 S. Karger AG, Basel

\section{Introduction}

Alzheimer's disease (AD) is the most common neurodegenerative disease worldwide, characterized by progressive memory loss and cognitive dysfunction. At the molecular level, AD is defined by the presence of extracellular aggregates of amyloid beta $(\mathrm{A} \beta)$ peptide, especially the 42-amino-acid-long form (A $\left.\beta_{1-42}\right)$, and of intracellular neurofibrillary tangles of tau protein, which correlate with cognitive deficits in advanced $\mathrm{AD}$ patients [1]. There 
is currently no treatment to stop or to revert $\mathrm{AD}$ progression, and our limited knowledge on the onset of the disease hampers the development of $\mathrm{AD}$-specific drugs.

Accumulating evidence suggests that $\mathrm{AD}$ involves a metabolic component, with pronounced impairment in brain glucose metabolism [2] and altered response to hormones involved in metabolism [3,4]. The link between metabolic dysfunction and $\mathrm{AD}$ is further supported by the fact that type 2 diabetes (T2D) and middle-life obesity significantly increase the risk of developing $\mathrm{AD}[5,6]$. Altered levels of the hormone leptin and/or dysfunction of leptin signaling is frequently observed in both metabolic disorders like T2D and obesity as well as in $\mathrm{AD}$ [7]. These data suggest that metabolic dysfunction might be a noncognitive early symptom of AD. Accordingly, transgenic mice lacking leptin receptor $(d b / d b$ mice) or deprived of leptin production ( $o b / o b$ mice) show significant cognitive impairment in their adulthood [8-11]. Importantly, mice obtained by crossing the $d b$ or $o b$ mice with an $\mathrm{AD}\left(\mathrm{APP} \mathrm{P}^{\Delta \mathrm{NL} / \Delta \mathrm{NL}} \times \mathrm{PS}^{\mathrm{P} 264 \mathrm{~L} / \mathrm{P} 264 \mathrm{~L}}\right)$ mice model $(d b / A D$, $o b / A D)$ display more pronounced and earlier impairment in learning and memory performance, as well as earlier metabolic dysfunction $[12,13]$. The link between these pathologies seems therefore to be bidirectional, with one facilitating the development of the other. At the molecular level, however, little is known on the mechanisms underlying such interactions.

Leptin is a polypeptide hormone primarily produced by adipocytes that regulates food intake and energy metabolism by acting in the hypothalamus. Leptin effects are mediated by its membrane receptor - LepR, which belongs to the cytokine receptor class I family. Although different isoforms of LepR can be generated by alternative splicing, the long isoform LepRb is thought to be the main isoform mediating leptin signaling (reviewed by Peelman et al. [14]). LepR activation and signaling need to be tightly regulated to maintain glucose and energy homeostasis (reviewed by Roujeau et al. [15]). Excessive leptin levels lead to the development of leptin resistance and metabolic disorders [16, 17].

A growing body of evidence shows that leptin functions go beyond food intake control and also regulate neuronal activity and plasticity. LepR is not only expressed in the hypothalamus, the main center of energy regulation, but also in the cortex and hippocampus, 2 major brain regions affected in $\mathrm{AD}[18,19]$. Leptin administration is able to improve cognitive performance [20] and confers neuroprotection against glutamate toxicity [21], brain ischemic injury [22], and apoptosis induced by nutrient deprivation [23] or 6-hydroxydopamine [24]. In humans, leptin replacement therapy of subjects with congenital leptin deficiency rescues structural brain abnormalities, neuronal activity, and cognitive deficits [25-27]. Whereas it is still controversial whether circulating leptin levels are increased or decreased in $\mathrm{AD}$ patients [7,28], a deficit in the leptin response due to decreased expression of LepR and downstream signaling molecules is commonly acknowledged with $\mathrm{AD}$ progression $[4,7,29]$. Accordingly, altered food intake and energy expenditure have been reported in $\mathrm{AD}$ models [30-32] indicating a deficient leptin response. However, direct information on the functional status of the LepR in $\mathrm{AD}$ and on the precise connection between the leptin system and $\mathrm{AD}$-related pathological mechanisms are still missing. Here, we show that LepR is directly targeted by $\mathrm{A} \beta$ oligomers, which dampens leptin signaling through negative allosteric modulation upon binding to LepR, ultimately impacting the responsiveness of hypothalamic neurons to this hormone.

\section{Materials and Methods}

\section{Cell Culture}

HEK293T and N46 cell lines were maintained in DMEM Glutamax (Invitrogen) culture medium supplemented with 10\% FBS at $37^{\circ} \mathrm{C}\left(95 \% \mathrm{O}_{2}, 5 \% \mathrm{CO}_{2}\right)$. Cells seeded in $\mathrm{P} 6$ well plates were transfected with plasmids coding to SNAP-LepRa, SNAP-LepRb, or SNAP-EGFR receptors using the jetPEI reagent, according to the supplier's instructions (Polyplus-Transfection, New York, NY, USA).

\section{Preparation of $A \beta$ Oligomers}

Lyophilized $\mathrm{A} \beta_{1-42}$ was dissolved in 1,1,1,3,3,3-hexafluoro2-propanol, aliquoted and reconstituted in anhydrous DMSO and PBS prior to use. The peptide solution was incubated for $24 \mathrm{~h}$ at $4^{\circ} \mathrm{C}$ to generate oligomers, as previously described [33].

\section{In vivo $A \beta$ Model}

Male Swiss CD-1 mice, aged 7-9 weeks and weighing $32 \pm 2 \mathrm{~g}$ (Janvier, St Berthevin, France) were housed in the animal facility of the University of Montpellier (CECEMA, registration number D34-172-23), in a temperature and humidity controlled facility on a $12 \mathrm{~h} / 12 \mathrm{~h}$ light/dark cycle (lights on at 7:00 h) with access to food and water ad libitum. The amyloid $\beta_{25-35}$ peptide $\left(A \beta_{25-35}\right)$ and scrambled $\mathrm{A} \beta_{25-35}$ peptide (Eurogentec, Angers, France) were solubilized in sterile distilled water $(3 \mathrm{mg} / \mathrm{mL})$ and stored at $-20^{\circ} \mathrm{C}$. Before injection, peptides were aggregated by incubation at $37^{\circ} \mathrm{C}$ for 4 days. They were administered under isoflurane anesthesia, intracerebroventricularly in a volume of $3 \mu \mathrm{L}$ per mouse according to the previously published method $[34,35]$. The following day, mice were i.p. injected with either saline (control) or leptin $(2 \mathrm{mg}$ / $\mathrm{kg}$ body weight) and sacrificed by cervical dislocation after $30 \mathrm{~min}$. Brain tissue was immediately dissected to collect the hippocampus and hypothalamus, and samples were stored at $-80^{\circ} \mathrm{C}$ until analysis by Western blot. 


\section{SDS-PAGE}

Detection of signaling molecules was performed in lysates from cells or brain tissues prepared by homogenization in NP40 lysis buffer (50 mM Tris pH 7.4, $150 \mathrm{mM} \mathrm{NaCl}, 1 \mathrm{mM}$ EDTA, 1\% NP-40, $0.25 \%$ sodium deoxycholate, containing protease and phosphatase inhibitors). Protein level was quantified by the BCA method (ThermoFisher Scientific), and $50 \mu \mathrm{g}$ of protein was mixed in $2 \times$ Laemmli buffer. Denatured proteins $\left(95^{\circ} \mathrm{C}, 5 \mathrm{~min}\right)$ were resolved in $10 \%$ SDS-PAGE, transferred to nitrocellulose membranes, blocked in 5\% nonfat dried milk or 3\% BSA in TBS (10 mM Tris$\mathrm{HCl}, \mathrm{pH} 8,150 \mathrm{mM} \mathrm{NaCl}$ ) and immunoblotted with primary antibodies against the phosphorylated and total form of STAT-3 (Cell Signaling, Ref. 9145S and 9139S, Leiden, Netherlands), AKT (Cell Signaling, Ref. 587F11 and 4685), and ERK (P-ERK1/2 sc-7383; ERK2 sc-154; Santa-Cruz Biotechnology, Dallas, TX, USA) proteins (overnight, $4^{\circ} \mathrm{C}$ ), or against $\mathrm{A} \beta$ (6E10, 803001; Biolegend, San Diego, CA, USA). Immunoreactivity was revealed using secondary antibodies coupled to 680 or $800 \mathrm{~nm}$ fluorophores (1: 15,000 , diluted in $3 \%$ nonfat dried milk in TBS; LI-COR Biosciences, Lincoln, NE, USA), and readings were performed with the Odyssey LI-COR-IR fluorescent scanner (LI-COR Biosciences).

\section{Receptor Subdomains}

Recombinant human EGFR extracellular domain (ECD) was purchased from R\&D Systems (Ref. 344-ER, Minneapolis, MN, USA). LepR domains were produced using expression vectors coding for the different ECDs of the LepR coupled to a combined FLAG-His tag, as previously described [36]. The recombinant proteins were expressed in Freestyle 293-F cells and purified from the supernatants using the C-terminal $6 *$ His-tag with TALON metal affinity resin (Clontech). Imidazole (Merck) was used for elution and removed using PD-10 gel filtration columns (GE Healthcare). Protein concentrations were determined using the absorbance at $280 \mathrm{~nm}$ (Nanodrop; ThermoFisher Scientific, Waltham, MA, USA) and purity via SDS-PAGE. The correct folding of the ECDs into the biologically relevant conformations is attested by previous studies from our team in which the ECDs were used for structural studies by small-angle X-ray scattering [37], for leptin binding studies and to generate single-domain camelid antibodies able to recognize LepR in vitro and in vivo [38-40].

\section{AlphaLISA}

Intracellular phospho-ERK1/2 (Thr202/Tyr204), phospho-AKT, and phospho-STAT-3 were measured using the respective AlphaLISA kit (ALSU-PERK-A500, ALSU-PAKT-B500, ALSU-PST3A500; Perkin Elmer, Waltham, MA, USA). Briefly, 1 day after transfection, HEK293T or N46 cells were trypsinized and plated into 48well plates and serum-starved for $16 \mathrm{~h}$ prior to stimulation. After adding the ligand, plates returned to the incubator for the indicated incubation time. Plates were then placed on ice, medium was aspirated, and cells were lysed by adding $20 \mu \mathrm{L}$ of lysis buffer (provided by the manufacturer) and using cell scrapper. Lysates were added to a 384-well plate to run the assay according to the manufacturer's instructions. The plates were read using the Tecan Infinite M1000 PRO microplate reader (Tecan Group, Ltd., Männedorf, Switzerland).

Time-Resolved Fluorescence Resonance Energy Transfer Binding Assay

Cells expressing SNAP-tagged LepR were fluorescently labelled with the Terbium cryptate fluorophore (Tb; Lumi4-Tb; Cisbio
Bioassays, France) using the SNAP enzyme technology (Keppler et al. [51]). Cells were incubated with $10^{-7} \mathrm{M}$ of Tb-SNAP substrate in Tag-lite labeling medium $\left(1 \mathrm{~h}, 4^{\circ} \mathrm{C}\right)$, washed several times, detached using a Cell Dissociation buffer (13151014; ThermoFisher Scientific), collected, and distributed into 384-well plate. Cells were then incubated with fluorescently labeled A $\beta$-FAM oligomers (AS-23525; Anaspec, Fremont, CA, USA), or fluorescently labeled ligands of LepR (leptin-d2, LAN-d2, custom label by Cisbio Bioassays) in the presence or absence of competitors (2-4h, RT), and the time-resolved fluorescence resonance energy transfer (TRFRET) signal was read in the plate reader Tecan F500 (Tecan) (ex: $340 \mathrm{~nm} / \mathrm{em}$ : $520 \mathrm{~nm}$ (acceptor A $\beta$-FAM) or $665 \mathrm{~nm}$ (acceptor leptin-d2); and $620 \mathrm{~nm}$ (donor)). Data are expressed as acceptor/ donor ratio or normalized as percent of maximal binding (maximal TR-FRET ratio $=100 \%)$.

\section{BRET Assay}

HEK293T cells were transfected with expression plasmids coding for LepR fused to Renilla luciferase (Rluc) enzyme and LepR fused to yellow fluorescent protein (YFP), at 1:1 DNA ratio, or with increasing amounts of the energy acceptor (YFP-fused LepR) for saturation curves. Cells were plated in white 96-well microplates, and assays were performed $48 \mathrm{~h}$ after transfection, as previously described [41]. Briefly, culture medium was removed and replaced by phosphate-buffered saline, followed by addition of Rluc substrate (coelenterazine h, $5 \mu \mathrm{M}$; Ref. UPR30783; Interchim, Montluçon France) and incubation for 5 min before addition of leptin, when indicated. Plates were immediately read using a lumino/fluorometer (Mithras; Berthold Technologies), which allows sequential integration of Rluc (475-495 nm) and YFP (517-543 nm) emission signals. Bioluminescence resonance energy transfer (BRET) signal is expressed as excited YFP signal/Rluc signal ratio $\times 1,000$ to obtain miliBRET units $(\mathrm{mBU})$. $\mathrm{BRET}_{50}$ value refers to the acceptor/donor ratio concentration required to generate halfmaximal BRET signal and were obtained from saturation curves.

\section{Electrophysiology}

Pomc-Cre:ROSA-tdTomato mice were generated by breeding Pomc-Cre mice to ROSA-tdTomato mice purchased from The Jackson Laboratories (Pomc-cre line: 005965 - STOCK Tg(Pomc1cre)16Lowl/J; ROSA-tdTomato line: 007914 - B6.Cg-Gt(RO-

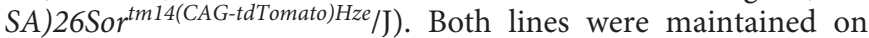
C57BL6 background, and Pomc-Cre driver and tdTomato Cre reporter mice were used in the heterozygous state for experiments.

Electrophysiological recordings were performed on living brain slices containing the tuberal region of the hypothalamus from 8- to 12-week-old transgenic Pomc-Cre::tdTomato mice as previously described [42]. Briefly, mice were anesthetized with isoflurane and decapitated. The brain was removed and rapidly placed in ice-cold artificial cerebrospinal fluid (ACSF) containing the following (in $\mathrm{mM}$ ): $120 \mathrm{NaCl}, 3.2 \mathrm{KCl}, 1 \mathrm{NaH}_{2} \mathrm{PO}_{4}, 26 \mathrm{NaH}-$ $\mathrm{CO}_{3}, 1 \mathrm{MgCl}_{2}, 2 \mathrm{CaCl}_{2}, 2.5$ glucose (290 mOsm, pH 7.4) and bubbled with $95 \% \mathrm{O}_{2}-5 \% \mathrm{CO}_{2}$. Three $250-\mu \mathrm{m}$ coronal hypothalamic slices containing the arcuate nucleus (ARC) were cut using a vibratome (VT1200; Leica). Slices were incubated at $34^{\circ} \mathrm{C}$ in oxygenated ACSF for a recovery period of $1 \mathrm{~h}$, and then at room temperature until recording. For the $A \beta$ experiments, scrambled control $A \beta$ or $A \beta_{1-42}$ were added to ACSF during the incubation period.

For patch-clamp recording, individual brain slices were placed in a recording chamber (Warner Instruments), immobilized by a 
nylon grid and continuously perfused at $3 \mathrm{~mL} / \mathrm{min}$ with oxygenated ACSF which is maintained at $32.8^{\circ} \mathrm{C}$ by a heater controller (TC-344C; Warner Instruments). Pro-opiomelanocortin (POMC) neurons were visualized and identified using a $\times 40$ magnification in an upright fluorescent microscope with infrared differential interference contrast (Leica DM-LFSA) and a digital camera (Hamamatsu Photonics). Recording pipettes were pulled from borosilicate glass capillaries ( $1.5 \mathrm{~mm}$ outer diameter; $1.12 \mathrm{~mm}$ inner diameter; World Precision Instruments) using P1000 Flaming Brown and had resistance from 4 to $6 \mathrm{M} \Omega$ when filled with an internal solution containing the following (in $\mathrm{mM}$ ): $123 \mathrm{~K}$-gluconate, $2 \mathrm{MgCl}_{2}, 8 \mathrm{KCl}$, 0.2 EGTA, $4 \mathrm{Na}_{2}$-ATP, $0.3 \mathrm{Na}-\mathrm{GTP}$, and 10 HEPES, pH 7.3 with $\mathrm{KOH}$. Pipettes were placed in contact with a POMC neuron using a PCS-5400 micromanipulator (Thorlabs). Whole-cell patch-clamp recordings were performed in the current-clamp mode by using a Multiclamp 700B Amplifier, digitized using the Digidata 1322A interface and acquired using pClamp 10.2 software (Molecular Devices). Data were filtered at $1 \mathrm{kHz}$ and sampled at $5 \mathrm{kHz}$.

To study the effect of $A \beta$ on neuronal response of POMC neurons to leptin or Glp1, leptin ( $20 \mathrm{nM})$ or Glp1 (20 nM) was applied to the perfusing system after a stable baseline recording. Recordings were analyzed with Clampfit 10.2 from pClamp software (Molecular Devices). For each recording, membrane potential and mean firing rate were determined before and during the bath application of leptin. Neurons were considered responsive when a change of $>20 \%$ in firing rate was observed. The peak response was determined, and the number of spikes was counted 2 min before and after the peak effect.

\section{Data and Statistical Analysis}

Data are presented as mean with SEM of the indicated $n$ number of independent experiments. Nonlinear regression and statistic tests were performed using GraphPad 6 software (GraphPad Software, version $6.0 \mathrm{~b}$ ). For data sets with equal variances, the parametric Student $t$ test was used to compare 2 groups, while analysis of variance (ANOVA) test, followed by Tukey's or Dunnett's multiple comparison test, was used to compare $>2$ groups. Two-way ANOVA, followed by Tukeys' multiple comparison test, was used to evaluate the interaction factor of the independent variables (control vs. A $\beta$ groups) on the dependent variable (leptin-induced response). Values of $p<0.05$ were considered statistically significant.

\section{Results}

\section{A $\beta$ Impairs Leptin Signaling in vitro and in vivo}

Leptin is known to activate several signaling pathways including the JAK2/STAT-3, PI3K/AKT, and ERK1/2 pathways $[43,44]$. In order to study the impact of soluble $\mathrm{A} \beta_{1-42}$ oligomers (oA $\beta$ ) - the pathologically most relevant species of $A \beta$ in $A D$ - on LepR function, we evaluated leptin signaling in the N46 mouse hypothalamic cell line [45] and in human embryonic kidney (HEK293) cells ectopically expressing the signaling competent LepRb isoform. Preparations of oA $\beta$ were characterized by Western blot, revealing the presence of oA $\beta$ migrating at an apparent MW of $17 \mathrm{kDa}$ and the absence of high $\mathrm{MW}$
$\mathrm{A} \beta$ aggregates (online suppl. Fig. S1a, b; see www. karger.com/doi/10.1159/000508105 for all online suppl. material). Stimulation of cells with leptin time-dependently increased the phosphorylation of STAT-3, AKT, and ERK1/2 with peak levels between 5 and $15 \mathrm{~min}$ (Fig. 1a, b). Preincubation of cells with oA $\beta$ largely diminished or prevented the leptin-induced effects in both cell types (Fig. 1a-d). The inhibitory effect of oA $\beta$ was not due to cell toxicity, as no significant cell death was detected up to $1 \mu \mathrm{M}$ oA $\beta$ (online suppl. Fig. S1c), or to decreased cell surface expression of LepRb (online suppl. Fig. 1d), known to impact the amplitude of LepR signaling [46]. oA $\beta$ preincubation had no effect on Il-6-induced STAT-3 phosphorylation (Fig. 1e, f), or on serum-induced AKT and ERK1/2 activation (Fig. 1g, h), excluding a general inhibitory effect of $A \beta_{1-42}$ on these signaling pathways. The inhibitory effect of oA $\beta$ on leptin $(1 \mathrm{nM})$-induced signaling at peak levels (15 min) was concentration-dependent with $\mathrm{IC}_{50}$ values in the low nanomolar range (Table 1), as assessed directly in cell lysates using the quantitative AlphaLISA technique (Fig. 1i-k).

These results were further confirmed in vivo in a previously described $\mathrm{A} \beta$-specific $\mathrm{AD}$ model, which is based on i.c.v. administration of the oligomeric $A \beta_{25-35}$ fragment $[34,35]$. Because $A \beta_{25-35}$ is more prone to form oligomers and aggregates than $A \beta_{1-42}$ while retaining comparable neurotoxic properties (reviewed by Millucci et al. [47]), it is the preferred and validated model for in vivo investigation of $A \beta$ effects in rodents due to the rapid development of cognitive impairment compared to full-length $A \beta_{1-42}$. In this accelerated $A D$ model, cognitive impairment is observed as early as 7 days post-injection, as also confirmed in our study using the Y-maze spontaneous alternation test (online suppl. Fig. 2a). In order to evaluate the acute effect of $A \beta$ on leptin signaling, $\mathrm{A} \beta_{25-35}$-treated mice received intraperitoneal administration of leptin (or saline as control) 1 day after the i.c.v. injection of $A \beta_{25-35}$. The same protocol was performed in mice injected with the scrambled $A \beta_{25-35}$ peptide $\left(A \beta_{\text {scr }}\right)$ as control. ERK1/2, STAT-3, and AKT activation was determined $30 \mathrm{~min}$ later in the hypothalamus and hippocampus, 2 brain areas relevant for metabolic control and cognitive performance, respectively (Fig. 11-o, online suppl. Fig. 2b, c). At this time point, there was no detectable leptin-induced ERK1/2 activation in those tissues (data not shown). In $A \beta_{25-35}$-injected animals, the basal STAT-3 phosphorylation level was increased in the hypothalamus and hippocampus compared to $A \beta_{\text {scr-injected }}$ animals (Fig. 1l-o, online suppl. Fig. 2b, c). Basal AKT phosphorylation was similar in both groups (Fig. 11-o, 

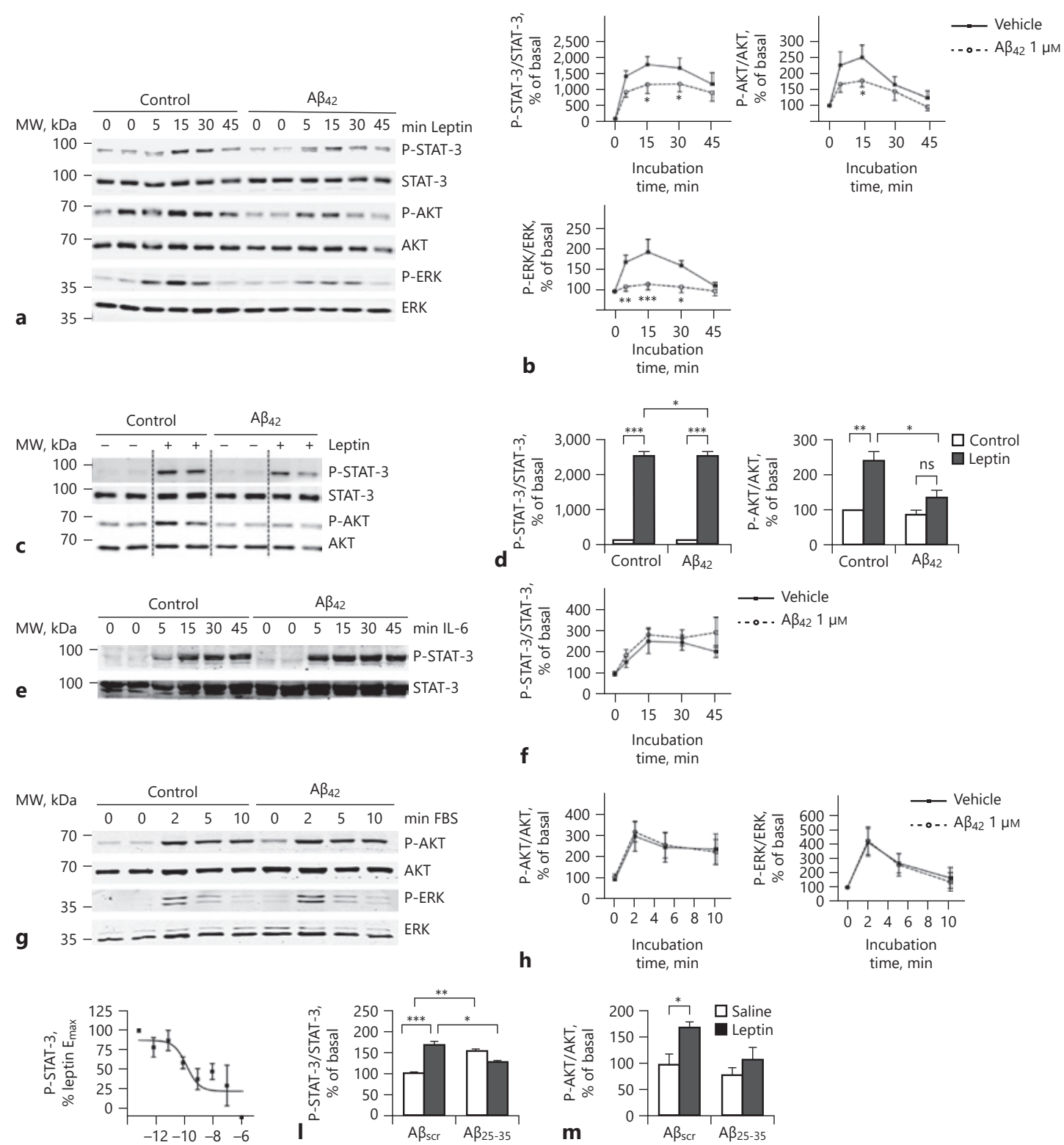

i $\log \left[A \beta_{42}\right], M$
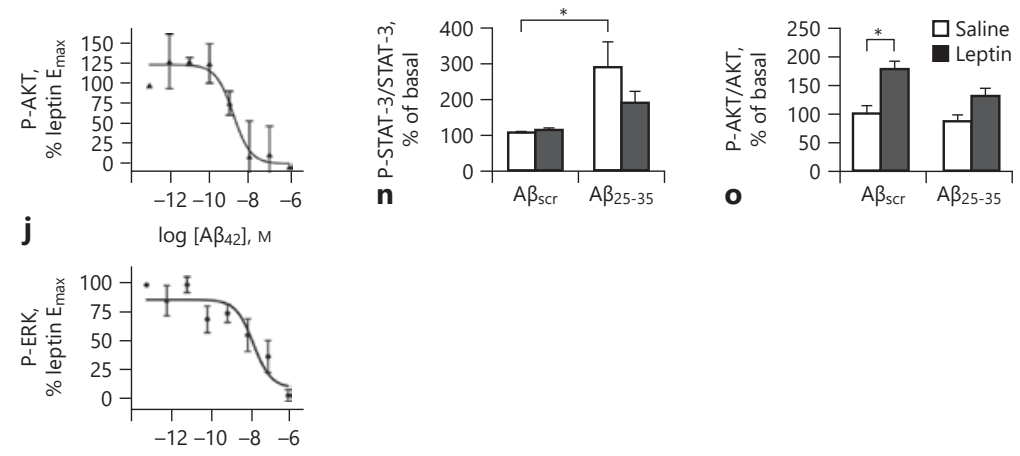

k

$\log \left[A \beta_{42}\right], M$ 
Table 1. Inhibitory effect of $A \beta$ on leptin-induced signaling pathways

\begin{tabular}{lll}
\hline & $\mathrm{pIC}_{50}$ & $\mathrm{I}_{\max }, \%$ \\
\hline P-STAT-3 & $9.7 \pm 0.5$ & $69.6 \pm 7.7$ \\
P-AKT & $8.8 \pm 0.4$ & $96.2 \pm 15.5$ \\
P-ERK & $7.7 \pm 0.3$ & $88.3 \pm 9.4$ \\
\hline
\end{tabular}

Concentration-response curves were analyzed by non-linear regression, and the potency of $A \beta$ inhibition on leptin-induced signaling activation is expressed as $\mathrm{pIC}_{50} \pm$ SEM. Maximal inhibition $\left(\mathrm{I}_{\max }\right)$ is expressed as a percentage (mean \pm SEM) of the maximal activation induced by leptin in the absence of $\mathrm{A} \beta$.

online suppl. Fig. $2 \mathrm{~b}, \mathrm{c})$. The effect of $\mathrm{A} \beta_{25-35}$ on STAT-3 activation could not be determined in the hippocampus as no leptin-induced STAT-3 activation was observed under our experimental conditions (Fig. 1n). In the hypothalamus, leptin treatment induced STAT-3 and AKT phosphorylation, as expected, in $\mathrm{A} \beta_{\text {scr-injected animals, }}$ and this effect was abolished in $A \beta_{25-35}$-injected animals (Fig. 11, m). In the hippocampus, leptin-induced AKT activation was similarly decreased in $\mathrm{A} \beta_{25-35}$-injected animals (Fig. 1o). Altogether, these data indicate that $A \beta$ oligomers induce spontaneous STAT-3 activation which is insensitive to leptin stimulation and inhibit leptin-induced AKT activation.

\section{$A \beta$ Binds Directly to the LepR}

$\mathrm{A} \beta$ oligomers have been shown to interact with various cellular components like lipids, sugars, and proteins [4850]. To explore the possibility of a direct binding of oA $\beta$ to LepR, we developed a TR-FRET-based oA $\beta$ binding assay. The assay is based on the energy transfer between the energy donor (terbium-labeled SNAP-LepR) and en-

Fig. 1. oA $\beta$ impairs leptin signaling. a Representative Western blot analysis of $A \beta_{1-42}(1 \mu \mathrm{M}, 2 \mathrm{~h})$ effect on leptin-induced phosphorylation of STAT-3, AKT, and ERK signaling molecules after 5, 15, 30 , and $45 \mathrm{~min}$ of incubation with leptin ( $5 \mathrm{nM}$ ) in HEK293T cells expressing LepRb receptor. b Quantification of data shown in a; data are expressed as mean \pm SEM of 5-7 independent experiments. ${ }^{*} p<0.05$; ${ }^{* *} p<0.01{ }^{* * *} p<0.001$ by two-way ANOVA test. c Representative Western blot analysis of $A \beta_{1-42}(1 \mu \mathrm{M}, 2 \mathrm{~h})$ effect on leptin-induced ( $5 \mathrm{nM}, 15 \mathrm{~min}$ ) phosphorylation of STAT3, AKT, and ERK signaling molecules in N46 cell line expressing LepRb receptor. $\mathbf{d}$ Quantification of data shown in c; data are expressed as mean \pm SEM of 3 independent experiments; ${ }^{*} p<0.05$; ** $p<0.01 ;{ }^{* * *} p<0.001$ by two-way ANOVA test. e Representative Western blot analysis of $A \beta_{1-42}(1 \mu \mathrm{M}, 2 \mathrm{~h})$ effect on IL-6-induced phosphorylation of STAT-3. f Quantification of data shown ergy acceptor (fluorescently labeled $A \beta_{1-42}$ oligomers, oA $\beta$-FAM), which occurs only if both are in close proximity to each other $(<10 \mathrm{~nm}$; Fig. 2a). SNAP is an O6-alkylguanine-DNA alkyl transferase, that catalyzes its own covalent binding to fluorescent derivatives of benzylguanine such as Lumi4-Tb [51]. Stoichiometric labeling of LepR is achieved by incubating cells expressing N-terminally SNAP-tagged LepR with Lumi4-Tb. The biological activity of both components, SNAP-LepR and oA $\beta$-FAM, has been previously validated $[33,52]$. Successful generation of oligomeric $\mathrm{A} \beta$-FAM was monitored by Western blot showing a similar migration pattern compared to unlabeled oA $\beta$ preparations (online suppl. Fig. S1b). Using this binding assay, we observed saturable binding of the oA $\beta$-FAM tracer to Lumi4-Tb-labelled SNAP-LepRb with nanomolar affinity $\left(K_{d}=169 \pm 64 \mathrm{nM}\right.$; Fig. $\left.2 b\right)$. Nonspecific binding was defined in the presence of an excess of nonlabeled oA $\beta(1 \mu \mathrm{M})$. A $\beta$-FAM binding was observed in a time- and $A \beta$-FAM concentration-dependent manner (Fig. $2 \mathrm{c}$ ), with $\mathrm{K}_{\mathrm{on}}$ and $\mathrm{K}_{\text {off }}$ values of $5.6 \times 10^{4}$ $\mathrm{M}^{-1} \mathrm{~min}^{-1}$ and $0.007 \mathrm{~min}^{-1}$, respectively. The calculated $\mathrm{K}_{\mathrm{d}}$ of $131 \mathrm{nM}\left(\mathrm{K}_{\mathrm{d}}=\mathrm{K}_{\mathrm{off}} / \mathrm{K}_{\mathrm{on}}\right)$ is in good agreement with the $K_{d}$ value determined at equilibrium.

Unlabeled oA $\beta$ showed high-affinity binding to LepRb in the subnanomolar range $\left(\mathrm{pK}_{\mathrm{i}}=10.7 \pm 0.4\right)$ as determined in competition binding experiments with the oA $\beta$-FAM tracer (Fig. 2d). Similar results were obtained with the short LepRa isoform $\left(\mathrm{pK}_{\mathrm{i}}=10.5 \pm 0.3\right)$, which contains the same ECD as LepRb (Fig. 2e). Taken together, these results show that $\mathrm{oA} \beta$ binds to the ECD of LepR with high affinity. Unlabeled $\mathrm{OA} \beta$ binds with sub-nanomolar affinity and the fluorescently labeled oA $\beta$-FAM with nanomolar affinity.

The hypothesis of oA $\beta$-FAM binding to the ECD of LepR was further confirmed as coincubation with the purified ECD of LepR prevented oA $\beta$-FAM binding to Lep-

in e; data are expressed as mean \pm SEM of 3 independent experiments. $\mathbf{g}$ Representative Western blot analysis of $\mathrm{A} \beta_{1-42}(1 \mu \mathrm{M}, 2$ h) effect on fetal bovine serum (FBS, 2\%)-induced phosphorylation of AKT and ERK in nontransfected HEK293T cells. $\mathbf{h}$ Quantification of data shown in $\mathbf{g}$; data are expressed as mean \pm SEM of 3 independent experiments. i-k Dose-dependent inhibition by $\mathrm{A} \beta_{1-42}$ ( 2 h) of leptin-induced phosphorylation of STAT-3 (i), AKT (j), and ERK (k) in HEK293T cells expressing LepRb, quantified by AlphaLISA assay; $n=3-5$. I-o Phospho- and total levels of STAT-3 and $\mathrm{AKT}$ in the hypothalamus $(\mathbf{I}, \mathbf{m})$ and hippocampus $(\mathbf{n}, \mathbf{o})$ of mice injected i.c.v with $A \beta_{25-35}$ or with control scrambled $A \beta$ ( $\left.A \beta s c r\right)$ following i.p. administration of saline (control) or leptin $(2 \mathrm{mg} / \mathrm{kg}$ body weight, $30 \mathrm{~min}$ ); $n=5$ mice per group; ${ }^{*} p<0.05$, ${ }^{* *} p<0.005$, ${ }^{* * *} p$ $<0.0001$ by two-way ANOVA test. Representative blots are shown in online supplementary Figure S2. ns, nonsignificant. 
SNAP-tag labeled with

Lumi4-Tb fluorophore
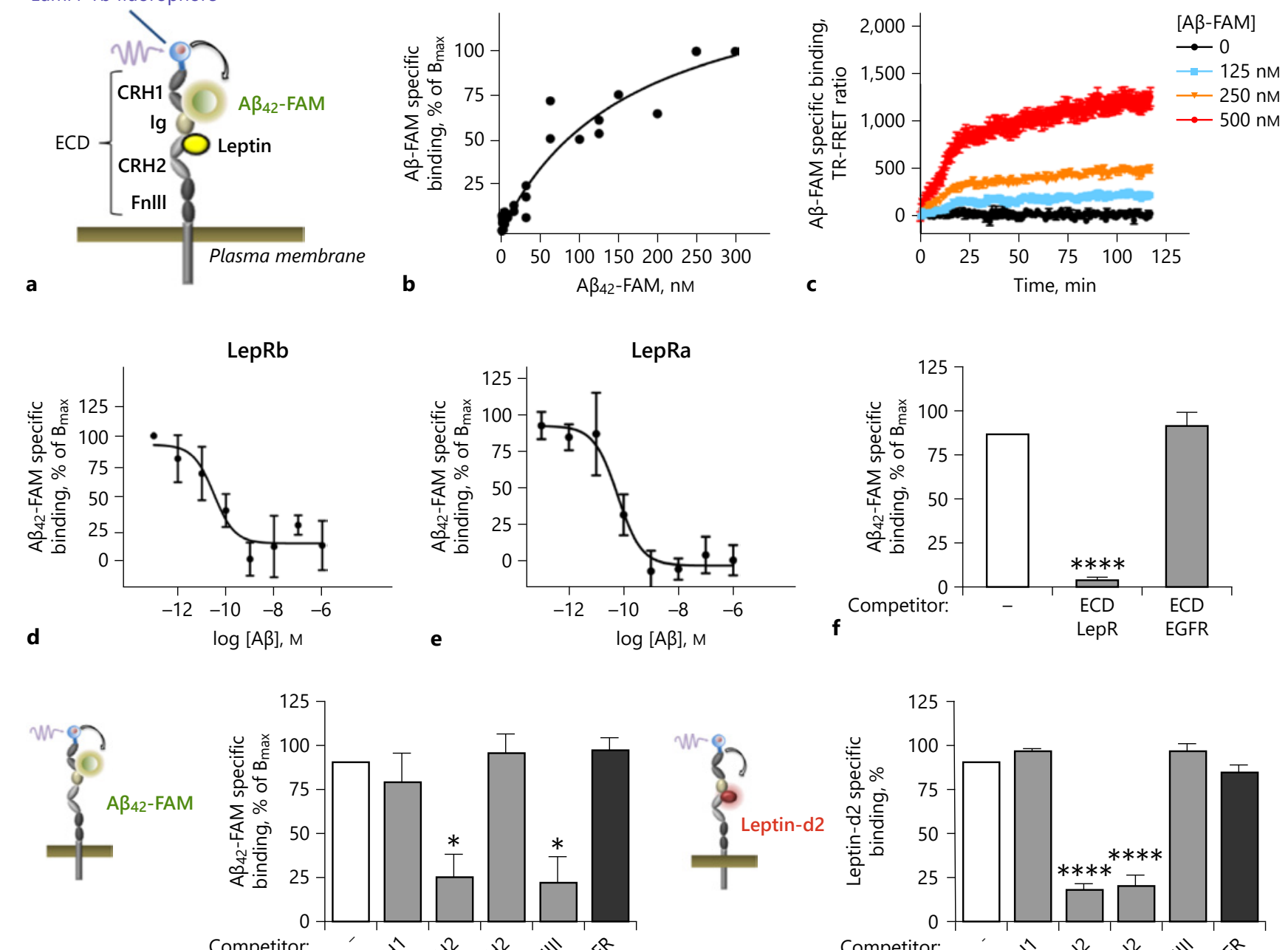

25
$75-$
$50-$
$25-$
0
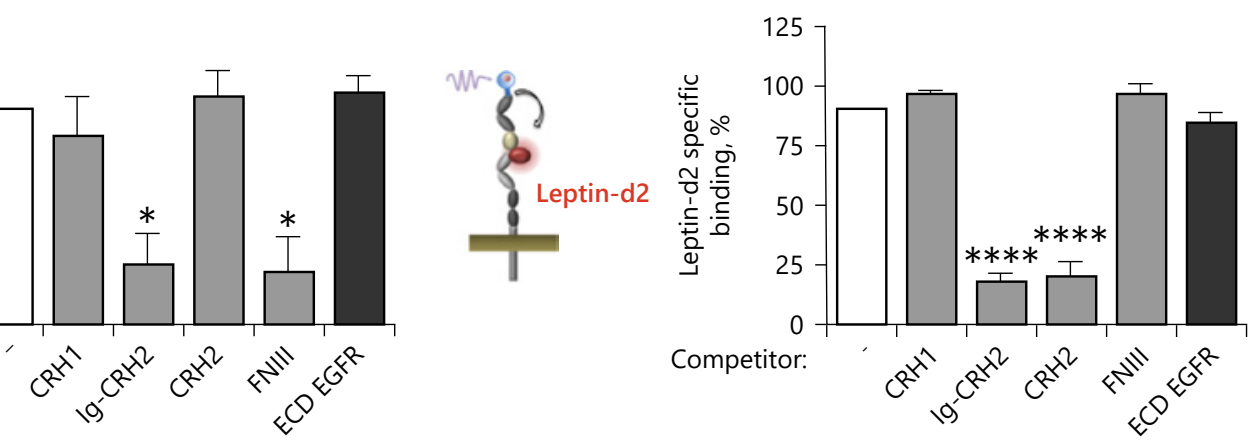

g

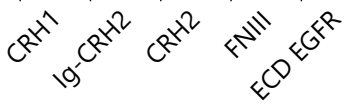

Ob-R subdomains

h

Ob-R subdomains

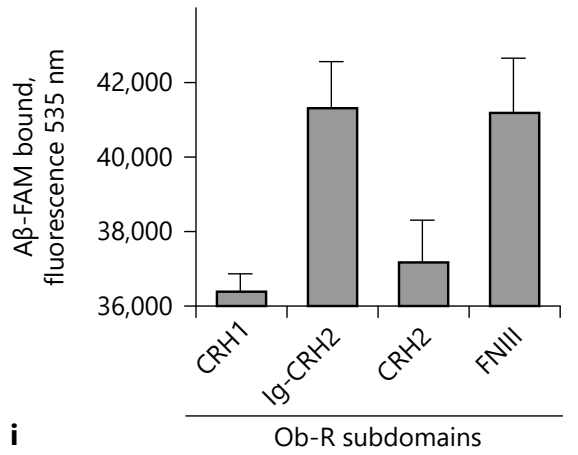

2

(For legend see next page.) 
Rb-expressing cells (Fig. 2f). A similar quantity of the ECD of the EGFR was without any effect (Fig. 2f). By using previously described subdomains of the ECD of LepR as competitors [38] in the oA $\beta$-FAM binding assay, we found that subdomains comprising the immunoglobulin (Ig)-like motif and the fibronectin III (FNIII) domains competed oA $\beta$ binding to LepR (Fig. 2g). When using fluorescently labeled leptin (leptin-d2) as tracer, only addition of subdomains containing the leptin binding-competent cytokine receptor homology (CRH)2 domain [53] expectedly prevented leptin- $\mathrm{d} 2$ binding to LepRb, thus validating the assay and the functionality of the CRH2 domain (Fig. 2h). Binding of oA $\beta$-FAM to Ig-like and FNIII domains was further confirmed in an in vitro binding assay by probing oA $\beta$-FAM binding to wells coated with different LepR ECDs (Fig. 2i). This strongly suggest direct binding of oA $\beta$-FAM to the Ig-like and FNIII domains of LepR and excludes the participation of any cellular component like lipids, sugars, or other proteins. Collectively, these data indicate that oA $\beta$ binds specifically to the Ig-like and FNIII domains of the ECD of LepR. These sites are distinct from the orthosteric highaffinity leptin binding site located in the $\mathrm{CRH} 2$ domain, thus indicating a possible allosteric binding mode of oA $\beta$.

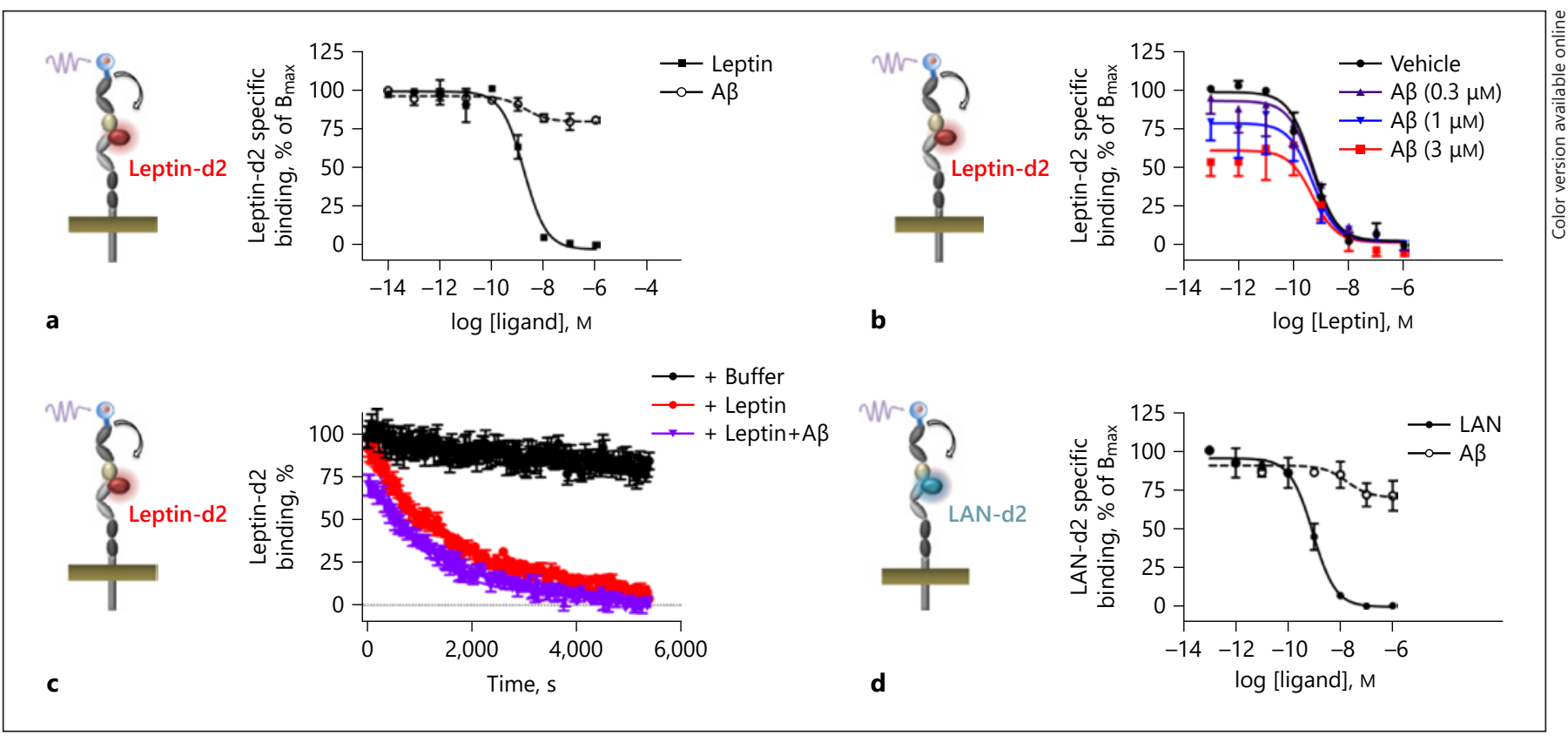

Fig. 3. oA $\beta$ allosteric modulation of leptin binding to LepR. a Competition of leptin-d2 binding to Tb-SNAP-LepR in HEK293T cells by increasing concentrations of nonlabelled leptin or A $\beta$ measured by TR-FRET. $\mathbf{b}$ Competition of leptin- $\mathrm{d} 2$ binding to $\mathrm{Tb}$ SNAP-LepR by increasing concentrations of nonlabelled leptin in the absence or presence of 3 different concentrations of $A \beta$. c Dis- sociation kinetics of leptin in the absence or presence of $A \beta(1 \mu \mathrm{M})$. d Competition of LAN-d2 binding to Tb-SNAP-LepR by increasing concentrations of nonlabelled LAN or $A \beta$ measured by TRFRET. Data are expressed as mean \pm SEM of at least 3 independent experiments, each performed in triplicates.
Fig. 2. oA $\beta$ binding to leptin receptor. a Scheme illustrating the TR-FRET-based A $\beta$-FAM binding assay to SNAP-tagged LepR labelled with Lumi-Tb, indicating the 4 subdomains of the extracellular domain of LepR (CRH1, Ig-like, CRH2, and FNIII). b Saturation binding curve of A $\beta$-FAM to Lumi-Tb-SNAP-LepR $(n=4)$. Nonspecific binding was defined in the presence of an excess of nonlabeled oA $\beta(1 \mu \mathrm{M})$. c Association kinetics of $A \beta$-FAM binding to Lumi-Tb-SNAP-LepR $(n=3)$. d, e Competition of A $\beta$-FAM binding to Tb-SNAP-LepRa (d) or Tb-SNAP-LepRb (e) by increasing concentrations of nonlabelled $A \beta$. Data are expressed as mean \pm SEM of at least 3 independent experiments, each performed in triplicates. $\mathbf{f}$ Competition of $\mathrm{A} \beta$-FAM binding to Tb-SNAPLepR by purified extracellular domain (ECD) of LepR or EGFR receptors; ${ }^{* * * *} p=0.0001$ by one-way ANOVA, $n=4$ independent experiments, each performed in triplicates. $\mathbf{g}, \mathbf{h}$ Competition of $\mathrm{A} \beta$-FAM (g) or leptin-d2 (h) binding to Tb-SNAP-LepR by purified subdomains of the LepR extracellular domain; $n=5$ independent experiments, each performed in triplicates; $* p<0.05, * * * * p$ $<0.0001$ by one-way ANOVA. Experiments shown in panels $\mathbf{b}-\mathbf{h}$ were performed in HEK293T cells transfected with SNAP-LepR. i ELISA binding of A $\beta$-FAM to 96-well black plate wells coated with purified subdomains of the LepR extracellular domain; $n=5$. 


\section{Allosteric Binding Mode of $A \beta$ to the LepR}

After having established that oA $\beta$ binds to LepR at a site distinct from the high-affinity leptin binding site in the $\mathrm{CRH} 2$ domain, we wanted to know whether leptin binding to LepR is allosterically modulated by oA $\beta$. We first measured the effect of oA $\beta$ on the binding of the leptin-d 2 tracer to the Lumi4-Tb-labelled SNAP-LepRb. oA $\beta$ concentration dependently inhibited leptin- $\mathrm{d} 2$ binding $\left(\mathrm{pIC}_{50}=8.7 \pm 0.4\right)$ with a maximal inhibition of 25.2 $\pm 2.4 \%$ compared to the reference competitor leptin (Fig 3a). This partial inhibition is compatible with an allosteric binding mode. Competition of the leptin- $\mathrm{d} 2$ tracer by leptin in the presence of different oA $\beta$ concentrations showed that $\mathrm{oA} \beta$ concentration dependently diminishes the $\mathrm{E}_{\max }$ but not the affinity $\left(\mathrm{pK}_{\mathrm{i}}\right)$ of unlabeled competitor leptin for LepR (Fig. 3b; Table 2). Finally, we performed kinetic ligand dissociation experiments to determine the off-rate $\left(\mathrm{K}_{\mathrm{off}}\right)$ of leptin in the absence or presence of oA $\beta$, a commonly used experimental setting to demonstrate an allosteric binding mode. oA $\beta$ increased the $\mathrm{K}_{\text {off }}$ of leptin by $24 \%$, from 0.0006373 to $0.0007885 \mathrm{~min}^{-1}(p=0.02)$ (Fig. 3c), proportionally decreasing therefore the half time $\left(t_{1 / 2}\right)$ of bound leptin and revealing a negative allosteric binding mode of oA $\beta$. The antagonist LAN is a mutated leptin [54] known to bind LepR at the same site and with the same affinity as leptin but without activating LepR [55]. The oA $\beta$ was similarly able to compete binding of the fluorescently labeled LepR antagonist LAN-d2 with a maximal inhibition of $26 \pm 6.3 \%$ and a $\mathrm{pIC}_{50}$ of 7.7 \pm 0.7 (Fig. 3d). Collectively, these results indicate a negative allosteric effect of oA $\beta$ on leptin binding to LepR.

\section{A $\beta$ Is a Negative Allosteric Modulator of LepR}

\section{Function}

We next evaluated the effect of oA $\beta$ on LepR function. The first events induced by leptin binding are intramolecular conformational changes and clustering of preformed LepR dimers $[41,56]$. Both events can be monitored with the previously described BRET assay measuring the proximity between 2 LepR fusion proteins, fused either to the Rluc energy donor or the YFP energy acceptor at their C-termini [41] (Fig. 4a).

To evaluate the effect of oA $\beta$ on preexisting LepR dimers, we performed BRET donor saturation experiments by coexpressing a constant amount of the LepR-Rluc and increasing amounts of LepR-YFP. Progressive interaction and saturation of the LepR-Rluc donor by the LepRYFP acceptor is observed, and oA $\beta(1 \mu \mathrm{M})$ does not modify this basal BRET signal at any donor/acceptor ratio (Fig. 4b). Accordingly, the calculated $\mathrm{BRET}_{50}$ value, cor-
Table 2. Efficiency and affinity of leptin binding to LepR in the absence or presence of $A \beta$

\begin{tabular}{|c|c|c|c|c|}
\hline & Leptin & $\begin{array}{l}\text { Leptin + } \\
\mathrm{A} \beta(0.3 \mu \mathrm{M})\end{array}$ & $\begin{array}{l}\text { Leptin }+ \\
\mathrm{A} \beta(1 \mu \mathrm{M})\end{array}$ & $\begin{array}{l}\text { Leptin + } \\
\mathrm{A} \beta(3 \mu \mathrm{M})\end{array}$ \\
\hline $\mathrm{pK}_{\mathrm{i}}$ & $10 \pm 0.1$ & $9.7 \pm 0.2$ & $10 \pm 0.3$ & $9.4 \pm 0.3$ \\
\hline $\mathrm{B}_{\max }, \%$ & 100 & $90.7 \pm 5.6$ & $79.6 \pm 6.5^{*}$ & $58.8 \pm 5.7^{*}$ \\
\hline
\end{tabular}

$* p<0.05$ compared to leptin group by $\mathrm{F}$ test. Concentrationresponse curves were analyzed by non-linear regression, and the affinity of leptin to LepR is expressed as $\mathrm{pKi} \pm$ SEM. Maximal leptin- $\mathrm{d} 2$ binding $\left(\mathrm{B}_{\max }\right)$ is expressed as percentage (mean $\pm \mathrm{SEM}$ ).

responding to the natural relative propensity of the 2 receptors to interact with each other is unaffected by oA $\beta$ $\left(\mathrm{BRET}_{50}=357.9 \pm 66.7\right.$ and $325.0 \pm 60.9$; without and with $\mathrm{oA} \beta$, respectively). Taken together, these results suggest that, despite the fact that oA $\beta$ binds to the inactive form of LepR in the absence of ligand, it does not interfere with LepR dimerization in the basal state nor does it induce any detectable conformational change.

We then determined the effect of oA $\beta$ on the leptinactivated LepR. Leptin increased the BRET signal in a concentration-dependent manner at a LepR donor/acceptor ratio close to the $\mathrm{BRET}_{50}$ as previously reported [41] (Fig. 4c). In the presence of oA $\beta$, the leptin response curve was right-shifted, and the maximal $B R E T$ value was diminished (Fig. 4c). At 1 nM leptin $\left(\mathrm{EC}_{50}\right)$, oA $\beta$ concentration dependently diminished the leptin-induced BRET with a $\mathrm{pIC}_{50}$ in the nanomolar range $\left(\mathrm{pIC}_{50}=7.7 \pm 0.2\right)$ reaching a plateau corresponding to approximately $50 \%$ of the leptin BRET signal (Fig. 4d). This result suggests that oA $\beta$ significantly modifies the conformation of LepR adopted in the presence of leptin.

We then validated the negative allosteric action of oA $\beta$ on LepR function by evaluating the effect of oA $\beta$ on different LepR signaling pathways (Fig. $4 \mathrm{e}-\mathrm{g}$ ). Leptin induced the phosphorylation of STAT-3, AKT, and ERK1/2 with $\mathrm{pEC}_{50}$ values of $9.4 \pm 0.3,10.3 \pm 0.2$ and $9.0 \pm 0.3$, respectively, in transfected neuronal N46 cells. The presence of different oA $\beta$ concentrations showed a tendency to shift the concentration-response curves to the right and significantly diminished the maximal potency $\left(\mathrm{E}_{\max }\right)$ by $50-70 \%$ of the leptin response depending on the pathway (Fig. 4e-g; Table 3). Altogether, these data support the definition of $\mathrm{oA} \beta$ as a negative allosteric modulator (NAM) of LepR on the STAT-3, AKT, and ERK signaling pathways. 

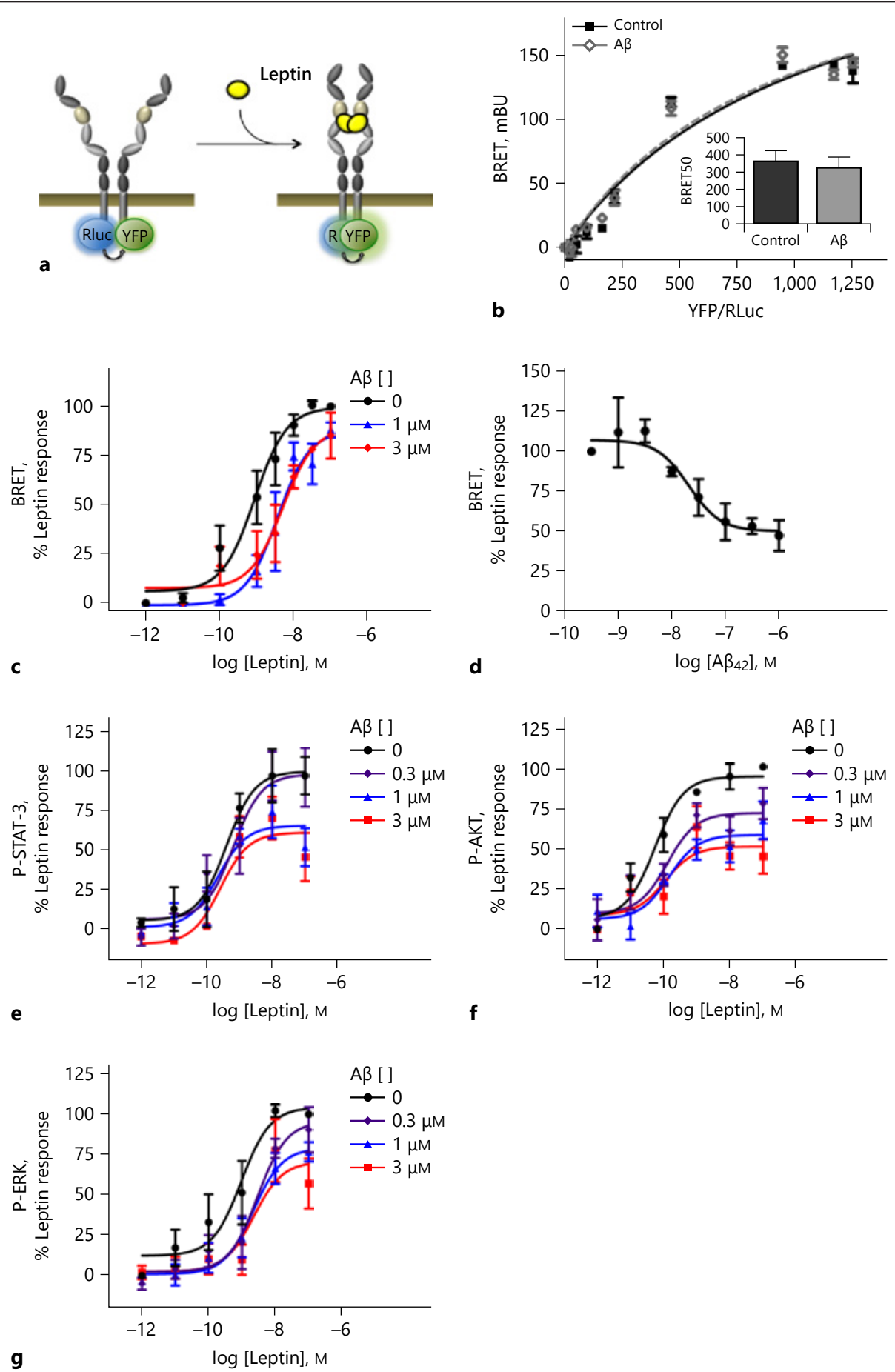

Fig. 4. $\mathrm{o} A \beta$ allosteric modulation of leptin-induced LepR conformational change and signaling. a Scheme of BRET assay between LepRfused Renilla luciferase (Rluc, donor) and LepR-fused-YFP (acceptor). $\mathbf{b}$ Representative BRET donor/acceptor saturation curve in the absence (control) or presence of $A \beta$. Insert BRET $_{50}$ values. Data are expressed as mean $\pm \mathrm{SD}$; similar results were observed in 3 independent experiments, each performed in triplicates. c Concentrationresponse curve of leptin-induced BRET signal in the absence or pres- ence of $A \beta$. Data are expressed as mean \pm SEM of 4 independent experiments, each performed in triplicates. $\mathbf{d}$ Concentration-dependent curve of $A \beta$ on leptin-induced BRET signal. Data are expressed as mean \pm SEM of 3 independent experiments, each performed in triplicates. e-g Allosteric modulation of $A \beta$ on leptin-induced phospho-STAT-3 (e), phospho-AKT (f), and phospho-ERK (g) measured by AlphaLISA. Data are expressed as mean \pm SEM of 5 independent experiments, each performed in duplicates. 
Table 3. Negative allosteric modulation of $A \beta$ on leptin-induced signaling pathways

\begin{tabular}{ccccc}
\hline & Leptin & $\begin{array}{c}\text { Leptin }+ \\
\mathrm{A} \beta(0.3 \mu \mathrm{M})\end{array}$ & $\begin{array}{c}\text { Leptin }+ \\
\mathrm{A} \beta(1 \mu \mathrm{M})\end{array}$ & $\begin{array}{c}\text { Leptin }+ \\
\mathrm{A} \beta(3 \mu \mathrm{M})\end{array}$ \\
\hline $\begin{array}{c} \\
\text { P-STAT-3 }\end{array}$ & & & & \\
pEC $_{50}$ & $9.4 \pm 0.3$ & $9.2 \pm 0.3$ & $9.6 \pm 0.3$ & $9.6 \pm 0.3$ \\
$\mathrm{E}_{\max }, \%$ & 100 & $98 \pm 12$ & $65.5 \pm 7.2^{*}$ & $61 \pm 7.5^{*}$ \\
P-AKT & & & & \\
pEC & $10.3 \pm 0.2$ & $9.8 \pm 0.3$ & $9.8 \pm 0.3$ & $9.9 \pm 0.5$ \\
$\mathrm{E}_{\text {max }}, \%$ & 100 & $72.3 \pm 5.8$ & $58.7 \pm 5.8^{*}$ & $51.5 \pm 6.9^{*}$ \\
P-ERK & & & & \\
pEC $_{50}$ & $9.0 \pm 0.3$ & $8.5 \pm 0.2$ & $8.7 \pm 0.2$ & $8.6 \pm 0.4$ \\
$\mathrm{E}_{\max }, \%$ & 100 & $95.6 \pm 10$ & $79.1 \pm 7.5^{*}$ & $70.7 \pm 12^{*}$ \\
\hline
\end{tabular}

$* p<0.05$ compared to leptin group by $\mathrm{F}$ test. Concentrationresponse curves were analyzed by non-linear regression, and the affinity of leptin to LepR is expressed as $\mathrm{pK}_{\mathrm{i}} \pm$ SEM. Maximal leptin- $\mathrm{d} 2$ binding $\left(\mathrm{B}_{\max }\right)$ is expressed as percentage (mean \pm SEM).

\section{A $\beta$ Impairs Neuronal Response to Leptin}

To investigate whether the observed negative allosteric effect of $\mathrm{oA} \beta$ on LepR function has an impact in a native context, we performed patch-clamp experiments on anorexigenic POMC neurons in slices of the hypothalamic ARC, one of the main leptin target cells [57]. To reveal a NAM effect, we studied the effect of $\mathrm{oA} \beta$ on a saturating concentration of leptin $(20 \mathrm{nM})$ in terms of LepR activation and signaling (Fig. 4). We evaluated the effect of oA $\beta$ in terms of membrane potential and neuronal firing. Under these conditions, leptin depolarized 6 out of 10 POMC cells by $2-6 \mathrm{mV}$, similar to what was previously reported [58] (Fig. 5a, d). Whereas preincubation of brain slices with scrambled control oA $\beta$ (A $\beta$-scrambled) did not modify the leptin effect ( 5 out of 8 POMC neurons were depolarized by leptin; Fig. 5b, e), preincubation with oA $\beta$ abolished the leptin-induced depolarization in 6 out of 6 neurons (Fig. 5c, f). Consistent with the aforementioned data, we found that bath application of $20 \mathrm{~nm}$ leptin increased the firing rate of POMC neurons in the presence or absence of scrambled oA $\beta$, but this response was markedly inhibited in the presence of oA $\beta$ (Fig. $5 \mathrm{~g}-\mathrm{i}$ ). In order

Fig. 5. Electrophysiological analysis of oA $\beta$ effect on leptin-induced activation of POMC neurons. a-c Whole-cell currentclamp recording showing that leptin increased the spontaneous firing activity of the POMC neurons in the absence (a) or presence (b) of scrambled $A \beta$ but was ineffective in brain slices preincubated with $A \beta_{1-42}$ peptide (c). d, e Membrane potential of ARC POMC neurons before and after bath application of leptin (20 nM) to verify the specificity of the oA $\beta$ effect, we performed identical experiments with glucagon-like peptide 1 (Glp1), a hormone that, similarly to leptin, elicits an excitatory response in POMC neurons [59]. As expected, Glp1 depolarized POMC neurons and increased their firing rate (Fig. 6a, c, e). Contrary to what was observed with leptin, the presence of oA $\beta$ in the bath did not alter the neuronal response to Glp1 (Fig. 6b, d, f). In summary, these data indicate that the inhibitory effect of $A \beta$ on the membrane depolarization and firing activity of POMC neurons is specific for the leptin-induced response and likely due to the NAM activity of oA $\beta$ on LepR.

\section{Discussion}

Accumulating evidence supports the notion that metabolic dysfunction is an integral part of $\mathrm{AD}$, for which the term type 3 diabetes has been proposed (reviewed by de la Monte [60]). Here, we investigated whether $A \beta$ oligomers $(\mathrm{oA} \beta$ ) could contribute to the metabolic dysfunction observed in $\mathrm{AD}$ by targeting a key player of energy and glucose homeostasis, the LepR. We show that oA $\beta$ directly binds to the Ig-like and the FNIII modules of the ECD of LepR. We show that allosteric binding of oA $\beta$ interferes with leptin binding and inhibits leptin-induced intracellular signaling in vitro and in vivo, as well as leptin-promoted depolarization of hypothalamic POMC neurons. Thus, oA $\beta$ behaves as a NAM of LepR function providing a plausible mechanistic explanation for the metabolic dysfunction, in particular for the contribution of the leptin system, observed in $\mathrm{AD}$ patients.

\section{Metabolic Dysfunction in AD}

Evidence for a link between $\mathrm{AD}$ and metabolic diseases in humans comes from different sources. Epidemiological studies show that mid-life obesity and T2D are associated with an increased risk to develop $\mathrm{AD}$, suggesting that metabolic dysfunctions could precede cognitive symptoms [61-65]. Among the genetic risk factors, the $\varepsilon 4$ allele of the apolipoprotein E (APOE4) gene, coding for a protein involved in lipid transport and metabolism,

in the presence of buffer (control, $\mathbf{d}, n=6$ from 4 mice), control scrambled $\mathrm{A} \beta$ (e, $n=5$ from 4 mice), and $\mathrm{A} \beta_{1-42}$ peptide (f, $n=6$ from 4 mice). $\mathbf{g}$, i Leptin-induced response on spontaneous firing rate in the presence of buffer $(\mathbf{g}, n=6)$, control scrambled $\mathrm{A} \beta$ (h, $n=5)$, and $\mathrm{A} \beta_{1-42}$ peptide $(\mathbf{i}, n=6)$. $p$ values from paired two-tailed Student $t$ test are indicated.

(For figure see next page.) 


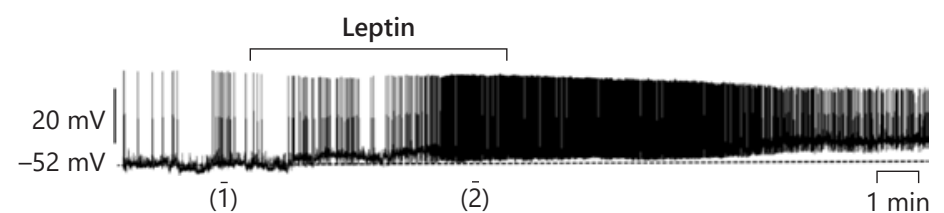

(1)

(2)

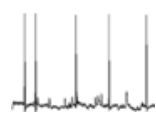

(1)

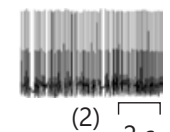

$1 \mathrm{~min}$

a

(2) $\sqrt{2 \mathrm{~s}}$
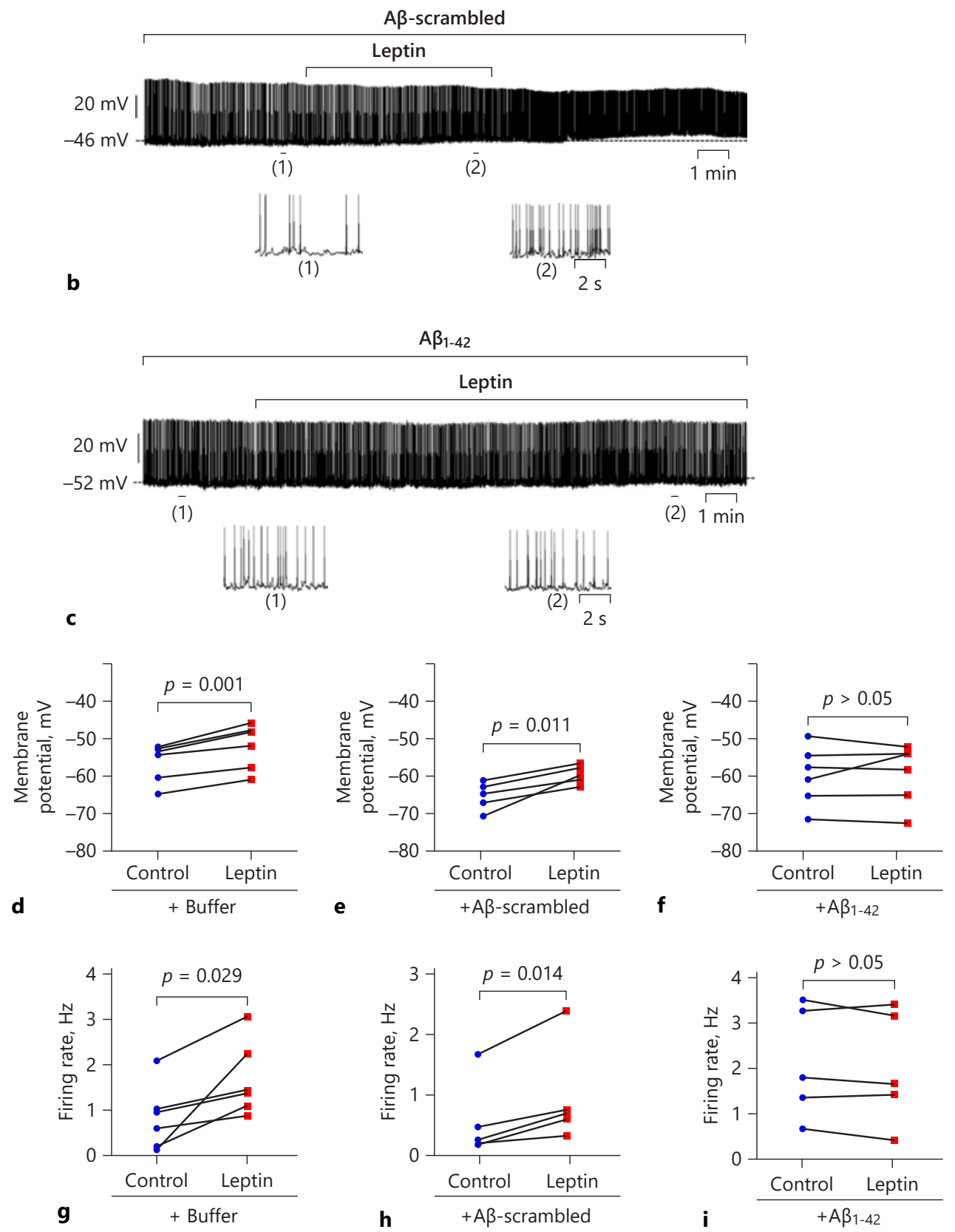
Fig. 6. Electrophysiological analysis of oA $\beta$ effect on Glp1-induced activation of POMC neurons. a, b Whole-cell currentclamp recording showing that Glp1 increased the spontaneous firing activity of the POMC neurons in both the absence (a) or presence (b) of $A \beta_{1-42}$ peptide. c, d Membrane potential of ARC POMC neurons before and after bath application of Glp1 $(20 \mathrm{nM})$ in the presence of buffer (control, c, $n=7$ from 4 mice), or $\mathrm{A} \beta_{1-42}$ peptide (d, $n=6$ from 4 mice). e, f GLP1 -induced response on spontaneous firing rate in the presence of buffer $(\mathbf{e}, n=7)$, or $\mathrm{A} \beta_{1-42}$ peptide $(\mathbf{f}, n=6)$. $p$ values from paired two-tailed Student $t$ test are indicated. a

(1)

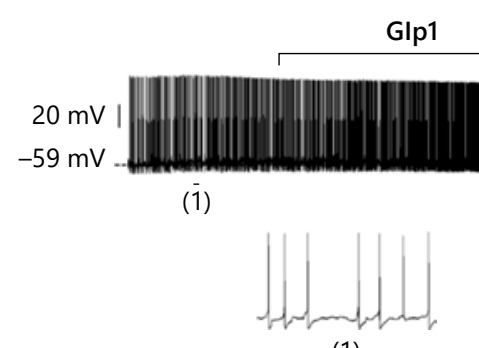

(2)

(2) $2 \mathrm{~s}$
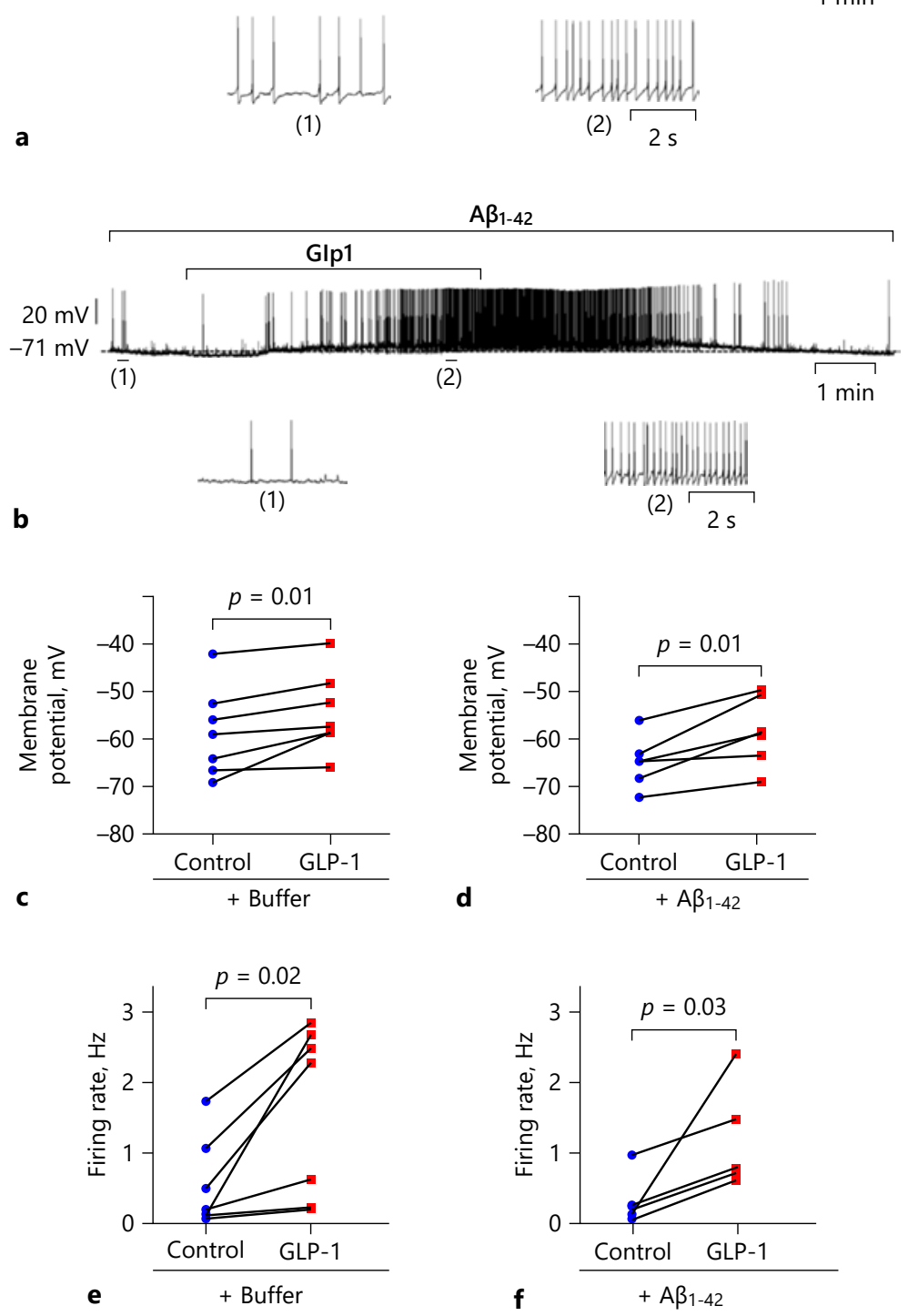

shows the strongest association with $\mathrm{AD}$, increasing up to 15 -fold the risk to develop $\mathrm{AD}$ (reviewed by Uddin et al. [66]). A $\beta$-induced neuroinflammatory response has been hypothesized as one of the connecting factors between $\mathrm{AD}$ and metabolic dysfunction, as it leads to impaired brain insulin signaling $[2,67]$, while a more direct molecular mechanism has not been described up to now. Here, we define LepR as a direct target of $A \beta$, revealing as well the first endogenous allosteric regulator of LepR.

\section{$A \beta$ Interaction with LepR and Other Receptors}

In addition to LepR, other receptors have been proposed to be targeted by $A \beta$, although this issue remains controversial due to technical limitations and to the tendency of $A \beta$ oligomers to interact with the cell membrane at high (micromolar to millimolar) concentrations [68]. Among the membrane proteins with evidence for direct binding to $A \beta$ are the cellular prion protein (Prpc), the leukocyte immunoglobulin-like receptor LilrB2, the 
Nogo-66 NgR1 receptor, and the ephrin type B receptor (EphB2) [69]. We recently developed a TR-FRET-based oA $\beta$ binding assay with largely improved specificity and robustness compared to previous assays allowing the detection of $\mathrm{A} \beta$ binding proteins with higher confidence [70]. The assay restricts the interaction detection window to $<10 \mathrm{~nm}$ (the maximal distance for energy transfer), thus minimizing the background signal of nonspecific interactions. This test allowed us to characterize the binding of oA $\beta$ to the nicotinic cholinergic $\alpha 7 \mathrm{nACh}$ receptor, another previously suggested $A \beta$ target [33], and to identify LepR as a direct target of oA $\beta$ (present study). Competition experiments showed that unlabeled oA $\beta$ displaced the oA $\beta$-FAM tracer with a $\mathrm{K}_{\mathrm{i}}$ value of $\sim 0.1 \mathrm{nM}$ for the short and long LepR isoforms. Binding of the oA $\beta$ FAM tracer itself was of lower, but still measurable, affinity $\left(\mathrm{K}_{\mathrm{d}} \sim 150 \mathrm{nM}\right)$. Because the oligomeric states of labeled and unlabeled $A \beta$ were very similar, we suspect that steric hindrance due to the introduction of the fluorescent group is at the origin of the reduced affinity of oA $\beta$-FAM. These nanomolar oA $\beta$ concentrations are compatible with those reported in AD patients [71]. Competition and direct binding experiments with the different modules of the ECD of LepR excluded the leptin binding-competent $\mathrm{CRH} 2$ subdomain, and unambiguously pointed towards the Ig-like and FNIII subdomains as oA $\beta$ binding domains. In our oA $\beta$-FAM binding experiments, however, we detected only one apparent binding site, which suggests that $\mathrm{o} A \beta$ probably displays very similar affinities for both domains. Previous studies showed that targeting specifically these 2 latter domains with neutralizing nanobodies leads to reduced LepR signaling [38], indicating their critical role in LepR function. Immunoglobulin and FNIII repeat domains were also previously suggested as $\mathrm{A} \beta$ binding sites in the LilrB2 [72] and the EphB2 receptor [73], respectively, suggesting a preferential affinity of $\mathrm{A} \beta$ to this type of domains. The presence of hydrophobic surfaces in those domains, as shown for the LilrB2 receptor [62], might be a common feature between $A \beta$ binding receptors. Whether this is the case for LepR awaits to be investigated, as no high-resolution structure of the LepR is available yet, apart from the isolated $\mathrm{CRH} 2$ subdomain.

Similarly to other cytokine receptors, like the growth hormone receptor [74], functional LepR comprises at least 2 receptor units constitutively interacting with each other in the basal state and has 2 asymmetrically placed ligand binding sites. Binding of leptin to the high-affinity binding site in the $\mathrm{CRH} 2$ subdomain primes low-affinity interaction of leptin with the Ig-like subdomain [37]. It is thus tempting to speculate that oA $\beta$ interferes

$\mathrm{A} \beta$ Impairs Leptin Function with leptin binding to this secondary site, hampering LepR activation. Nevertheless, $\mathrm{A} \beta$ binding to FNIII subdomains can also have important consequences for LepR activation, as they are involved in LepR dimerization through the formation of an intrareceptor disulfide bond involving Cys 604 [37]. Therefore, oA $\beta$ binding to this domain could interfere with the leptin-induced stabilization of the active LepR conformation, which is in line with our BRET results. Whether one or the other domain is more important for the inhibitory effect of $A \beta$ on LepR function remains to be elucidated. The negative allosteric nature of $o A \beta$ binding to LepR was first revealed in a series of competition and kinetic binding assays that showed a partial inhibitory effect of $A \beta$ on leptin binding and an increased $K_{\text {off }}$ of leptin in the presence of oA $\beta, 2$ established experimental settings to reveal an allosteric binding mode $[75,76]$. The NAM nature of the $A \beta$ effect was further confirmed on the functional level by the observed right shift of the leptin concentration curve in the BRET assay monitoring the leptin-induced conformational change and clustering of LepR, as well as in leptin concentration-response curves of STAT3, AKT, and ERK activation, where oA $\beta$ significantly decreased the maximal efficiency of leptin to activate the 3 pathways. Variation of $\mathrm{pIC}_{50}$ values for the different pathways indicate a differential sensitivity towards the inhibitory effect of oA $\beta$, most likely reflecting different capacities of the oA $\beta$-stabilized LepR conformation to activate the 3 signaling pathways.

\section{Consequences of the Negative Allosteric Modulation of} $A \beta$ on LepR

The relevance of such effect was evidenced in a physiologically relevant context by evaluating the response of hypothalamic neurons to leptin in the presence of oA $\beta$. Membrane depolarization and neuronal activity of POMC neurons in the ARC nucleus, which have been shown to mediate leptin effect on feeding and glucose homeostasis $[57,77]$, were significantly impaired by oA $\beta$, but not by the scrambled control oA $\beta$ peptide. Depolarization of arcuate POMC neurons by leptin has been shown to occur through activation of TRPC channels by the PI3K/AKT pathway [78]. A $\beta$ impairment of the leptin-induced AKT pathway activation probably underlies the absence of neuronal depolarization in response to leptin in our system. Interestingly, $A \beta$ did not alter the depolarization and firing response of these neurons to Glp1, indicating that $A \beta$ specifically targets the LepR. The effect of $A \beta$ is not restricted to the depolarizing action of leptin, as $A \beta$ has also been shown to impair leptin-in- 
duced hyperpolarization observed in other neuronal types, like NPY neurons [30, 79].

Collectively, these observations reveal the hypothalamus as an important target tissue for oA $\beta$, probably contributing to the metabolic alterations observed in $\mathrm{AD}[31$, 80].

Hypothalamic dysfunction in $\mathrm{AD}$ has been previously characterized, and it can be evidenced not only by altered metabolism regulation but also by the dysfunction of other processes regulated by hypothalamic cells, such as circadian rhythmicity and sleep behavior [31, 81]. These noncognitive dysfunctions were initially believed to be consequences of neurodegeneration in the hypothalamus, but it is currently recognized that such symptoms might appear decades before the cognitive symptoms. Our data now provide a molecular mechanism for early dysfunction of hypothalamic-dependent metabolism regulation through soluble oA $\beta$ impairment of LepR function. Accordingly, our results using the $A \beta$-specific accelerated $\mathrm{AD}$ model further confirm that leptin-induced increase in P-STAT-3 and P-AKT levels in the hypothalamus is impaired in $A \beta_{25-35}$-injected mice compared to mice injected with control scrambled $A \beta$ peptide. As activation of the STAT-3 pathway by leptin is important for body weight regulation $[82,83]$ and activation of the AKT/PI3K pathway for glucose homeostasis [84], $A \beta$ is likely to impact on both leptin-mediated hypothalamic effects. Consistently, both aspects are affected in $\mathrm{AD}$ models and patients [31].

Interestingly, $A \beta_{25-35}$-injected mice showed significant higher basal level of phosphorylated STAT-3 in both brain areas analyzed, that is, the hypothalamus and hippocampus, and leptin administration was not able to increase further. This effect was not observed in HEK293 cells, most probably because of differences in the responsiveness of the STAT-3 pathway in HEK293 cells versus an integrated systemic response of the hypothalamus and hippocampus. However, we cannot exclude a contribution of differences in the incubation time ( $2 \mathrm{~h}$ in vitro vs. 1 day in vivo) or the difference between $A \beta_{25-35}$ and $A \beta_{1-}$ 42. Of note, increased basal levels of phosphorylated STAT-3 in these brain areas are observed in animal models of high-fat diet-induced obesity and are associated with leptin and insulin resistance [85-87]. Thus, we can postulate that $\mathrm{A} \beta$-induced increase in basal phosphoSTAT-3 could participate in the leptin and insulin resistance observed in $\mathrm{AD}$ patients.

In addition to the hypothalamus, LepRs have been shown to be expressed in other brain areas, such as in the midbrain and hippocampus, where the leptin signal regu- lates food reward-induced feeding behavior and synaptic plasticity, respectively [88]. It will be interesting to see whether the presence of $A \beta$ alters also functions in these brain regions. Indeed, leptin-induced AKT activation in the hippocampus was also impaired by oA $\beta$, which probably contributes to $\mathrm{AD}$ development by counteracting the beneficial cognitive properties of leptin signaling in this brain region [89].

\section{Conclusion and Perspective}

Given the extremely low success rate to develop $\mathrm{AD}$ therapies, defining specific direct targets of $A \beta$, such as LepR, can open new therapeutic paths. Interestingly, improvement of the leptin response has been previously suggested to have a therapeutic value to treat $\mathrm{AD}$ by improving neuronal survival and hippocampal function and decreasing the accumulation of pathological forms of $A \beta$ and tau ([90-92]; reviewed by Maletínská et al. [93]). Therefore, preventing or inhibiting the interaction of $A \beta$ with LepR is expected to improve the responsiveness of the leptin system, with beneficial effects on metabolic regulation and presumably also on cognitive functions.

Altogether, we demonstrated high-affinity binding of $A \beta$ to the ECD of LepR, common to all receptor isoforms, and developed an $A \beta$ binding assay for LepR that might be useful to screen in the future for molecules interrupting this interaction. We show that $A \beta$ is a NAM of LepR with inhibitory effects visible at the level of leptin binding, LepR signaling through STAT-3, AKT and ERK1/2 pathways, and neuronal function. We expect that the new TR-FRET assay will assist drug development programs and increase the success rate of drug candidates in the $\mathrm{AD}$ field.

\section{Acknowledgments}

We are grateful to Eric Trinquet (Cisbio, France) for providing leptin-d2, LAN-d2, and SNAP-tagged human LepR and to Hui Chen (Institut Cochin) for help with Western blot experiments. We thank the CECEMA-UM animal facility.

\section{Statement of Ethics}

All animal procedures were conducted in strict adherence to the European Union Directive 2010/63 and the ARRIVE guidelines [94] and authorized by the National Ethic Committee (Paris). 


\section{Disclosure Statement}

The authors have no conflicts of interest to declare.

\section{Funding Sources}

This work was supported by Association France Alzheimer (grant No. 1610 and No. 2042), Distalz and EGID, the LABEX "Who am I?" laboratory of excellence ANR-11-LABX-007, funded by the French Government through its "Investments for the Future" program operated by The French National Research Agency (Agence Nationale de la Recherche) under Grant ANR-11-
IDEX-0005-01, the Institut National de la Santé et de la Recherche Médicale (INSERM), the Centre National de la Recherche Scientifique (CNRS), and the Fondation Philippe Chatrier Price 2015 awarded to E.C. M.C. was supported by a doctoral fellowship from the Guangzhou Elites Scholarship Council (China).

\section{Author Contributions}

E.C., T.M., V.P., J.D., and R.J. conceptualization. E.C., T.L., T.M., M.L., M.C., A.S., J.W., and L.Z. biochemical investigation. E.C., J.D., and R.J. writing - original draft. E.C., T.M., J.T., J.D., and R.J. writing - review and editing. E.C., M.C., V.P., J.D., and R.J. funding acquisition. E.C., J.T., V.P., J.D., and R.J. supervision.

\section{References}

1 Long JM, Holtzman DM. Alzheimer Disease: An Update on Pathobiology and Treatment Strategies. Cell. 2019 Oct;179(2):312-39.

2 De Felice FG, Lourenco MV. Brain metabolic stress and neuroinflammation at the basis of cognitive impairment in Alzheimer's disease. Front Aging Neurosci. 2015 May;7:94.

3 Zhao WQ, Townsend M. Insulin resistance and amyloidogenesis as common molecular foundation for type 2 diabetes and Alzheimer's disease. Biochim Biophys Acta. 2009 May;1792(5):482-96.

4 Maioli S, Lodeiro M, Merino-Serrais P, Falahati F, Khan W, Puerta E, et al.; Alzheimer's Disease Neuroimaging Initiative. Alterations in brain leptin signalling in spite of unchanged CSF leptin levels in Alzheimer's disease. Aging Cell. 2015 Feb;14(1):122-9.

$5 \mathrm{Xu}$ W, Qiu C, Gatz M, Pedersen NL, Johansson B, Fratiglioni L. Mid- and late-life diabetes in relation to the risk of dementia: a population-based twin study. Diabetes. 2009 Jan; 58(1):71-7.

6 Singh-Manoux A, Dugravot A, Shipley M, Brunner EJ, Elbaz A, Sabia S, et al. Obesity trajectories and risk of dementia: 28 years of follow-up in the Whitehall II Study. Alzheimers Dement. 2018 Feb;14(2):178-86.

7 Bonda DJ, Stone JG, Torres SL, Siedlak SL, Perry G, Kryscio R, et al. Dysregulation of leptin signaling in Alzheimer disease: evidence for neuronal leptin resistance. J Neurochem. 2014 Jan;128(1):162-72.

8 Stranahan AM, Arumugam TV, Cutler RG, Lee K, Egan JM, Mattson MP. Diabetes impairs hippocampal function through glucocorticoid-mediated effects on new and mature neurons. Nat Neurosci. 2008 Mar;11(3): 309-17.

9 Finger BC, Dinan TG, Cryan JF. Leptin-deficient mice retain normal appetitive spatial learning yet exhibit marked increases in anxiety-related behaviours. Psychopharmacology (Berl). 2010 Jul;210(4):559-68.

10 Dinel AL, André C, Aubert A, Ferreira G, Layé S, Castanon N. Cognitive and emotional alterations are related to hippocampal inflam- mation in a mouse model of metabolic syndrome. PLoS One. 2011;6(9):e24325.

11 Zhao Q, Matsumoto K, Tsuneyama K, Tanaka K, Li F, Shibahara N, et al. Diabetes-induced central cholinergic neuronal loss and cognitive deficit are attenuated by tacrine and a Chinese herbal prescription, kangen-karyu: elucidation in type 2 diabetes $\mathrm{db} / \mathrm{db}$ mice. J Pharmacol Sci. 2011;117(4):230-42.

12 Takeda S, Sato N, Uchio-Yamada K, Sawada K, Kunieda T, Takeuchi D, et al. Diabetes-accelerated memory dysfunction via cerebrovascular inflammation and Abeta deposition in an Alzheimer mouse model with diabetes. Proc Natl Acad Sci USA. 2010 Apr;107(15): 7036-41.

13 Niedowicz DM, Reeves VL, Platt TL, Kohler K, Beckett TL, Powell DK, et al. Obesity and diabetes cause cognitive dysfunction in the absence of accelerated $\beta$-amyloid deposition in a novel murine model of mixed or vascular dementia. Acta Neuropathol Commun. 2014 Jun;2(1):64.

14 Peelman F, Zabeau L, Moharana K, Savvides SN, Tavernier J. 20 years of leptin: insights into signaling assemblies of the leptin receptor. J Endocrinol. 2014 Oct;223(1):T923.

15 Roujeau C, Jockers R, Dam J. New pharmacological perspectives for the leptin receptor in the treatment of obesity. Front Endocrinol (Lausanne). 2014 Oct;5:167.

16 Knight ZA, Hannan KS, Greenberg ML, Friedman JM. Hyperleptinemia is required for the development of leptin resistance. PLoS One. 2010 Jun;5(6):e11376.

17 Zhao S, Zhu Y, Schultz RD, Li N, He Z, Zhang $Z$, et al. Partial Leptin Reduction as an Insulin Sensitization and Weight Loss Strategy. Cell Metab. 2019 Oct;30(4):706-19.e6.

18 Huang XF, Koutcherov I, Lin S, Wang HQ, Storlien L. Localization of leptin receptor mRNA expression in mouse brain. Neuroreport. 1996 Nov;7(15-17):2635-8.

19 Dhar M, Zhu M, Impey S, Lambert TJ, Bland $\mathrm{T}$, Karatsoreos IN, et al. Leptin induces hippocampal synaptogenesis via CREB-regulat- ed microRNA-132 suppression of p250GAP. Mol Endocrinol. 2014 Jul;28(7):1073-87.

20 Harvey J. Leptin regulation of neuronal morphology and hippocampal synaptic function. Front Synaptic Neurosci. 2013 Aug;5:3.

21 Dicou E, Attoub S, Gressens P. Neuroprotective effects of leptin in vivo and in vitro. Neuroreport. $2001 \mathrm{Dec} ; 12(18): 3947-51$.

22 Deng ZH, Liao J, Zhang JY, Liang C, Song CH, $\mathrm{Han} \mathrm{M}$, et al. Inhibition of the connexin $43 \mathrm{el}$ evation may be involved in the neuroprotective activity of leptin against brain ischemic injury. Cell Mol Neurobiol. 2014 Aug;34(6):871-9.

23 Russo VC, Metaxas S, Kobayashi K, Harris M, Werther GA. Antiapoptotic effects of leptin in human neuroblastoma cells. Endocrinology. 2004 Sep;145(9):4103-12.

24 Weng Z, Signore AP, Gao Y, Wang S, Zhang $\mathrm{F}$, Hastings $\mathrm{T}$, et al. Leptin protects against 6-hydroxydopamine-induced dopaminergic cell death via mitogen-activated protein kinase signaling. J Biol Chem. 2007 Nov; 282(47):34479-91.

25 Matochik JA, London ED, Yildiz BO, Ozata M, Caglayan S, DePaoli AM, et al. Effect of leptin replacement on brain structure in genetically leptin-deficient adults. J Clin Endocrinol Metab. 2005 May;90(5):2851-4.

26 Paz-Filho GJ, Babikian T, Asarnow R, Delibasi T, Esposito K, Erol HK, et al. Leptin replacement improves cognitive development. PLoS One. 2008 Aug;3(8):e3098.

27 Frank-Podlech S, von Schnurbein J, Veit R, Heni M, Machann J, Heinze JM, et al. Leptin Replacement Reestablishes Brain Insulin Action in the Hypothalamus in Congenital Leptin Deficiency. Diabetes Care. 2018 Apr;41(4):907-10.

28 Teunissen CE, van der Flier WM, Scheltens $P$, Duits A, Wijnstok N, Nijpels G, et al. Serum leptin is not altered nor related to cognitive decline in Alzheimer's disease. J Alzheimers Dis. 2015;44(3):809-13.

29 King A, Brain A, Hanson K, Dittmann J, Vickers J, Fernandez-Martos C. Disruption of leptin signalling in a mouse model of Alzheimer's disease. Metab Brain Dis. 2018 Aug; 33(4):1097-110. 
30 Ishii M, Wang G, Racchumi G, Dyke JP, Iadecola C. Transgenic mice overexpressing amyloid precursor protein exhibit early metabolic deficits and a pathologically low leptin state associated with hypothalamic dysfunction in arcuate neuropeptide $\mathrm{Y}$ neurons. J Neurosci. 2014 Jul;34(27):9096-106.

31 Ishii M, Iadecola C. Metabolic and Non-Cognitive Manifestations of Alzheimer's Disease: The Hypothalamus as Both Culprit and Target of Pathology. Cell Metab. 2015 Nov;22(5): 761-76.

32 Vandal M, White PJ, Chevrier G, Tremblay C, St-Amour I, Planel E, et al. Age-dependent impairment of glucose tolerance in the $3 \mathrm{xTg}$ $\mathrm{AD}$ mouse model of Alzheimer's disease. FASEB J. 2015 Oct;29(10):4273-84.

33 Cecon E, Dam J, Luka M, Gautier C, Chollet AM, Delagrange $\mathrm{P}$, et al. Quantitative assessment of oligomeric amyloid $\beta$ peptide binding to $\alpha 7$ nicotinic receptor. Br J Pharmacol. 2019 Sep;176(18):3475-88.

34 Maurice T, Lockhart BP, Privat A. Amnesia induced in mice by centrally administered beta-amyloid peptides involves cholinergic dysfunction. Brain Res. 1996 Jan;706(2):181-93.

35 Maurice T, Volle JN, Strehaiano M, Crouzier L, Pereira C, Kaloyanov N, et al. Neuroprotection in non-transgenic and transgenic mouse models of Alzheimer's disease by positive modulation of $\sigma 1$ receptors. Pharmacol Res. 2019 Jun;144:315-30.

36 Zabeau L, Defeau D, Iserentant H, Vandekerckhove J, Peelman F, Tavernier J. Leptin receptor activation depends on critical cysteine residues in its fibronectin type III subdomains. J Biol Chem. 2005 Jun;280(24):2263240.

37 Moharana K, Zabeau L, Peelman F, Ringler P, Stahlberg H, Tavernier J, et al. Structural and mechanistic paradigm of leptin receptor activation revealed by complexes with wild-type and antagonist leptins. Structure. 2014 Jun; 22(6):866-77.

38 Zabeau L, Verhee A, Catteeuw D, Faes L, Seeuws S, Decruy T, et al. Selection of noncompetitive leptin antagonists using a random nanobody-based approach. Biochem J. 2012 Jan;441(1):425-34.

39 Zabeau L, Jensen CJ, Seeuws S, Venken K, Verhee A, Catteeuw D, et al. Leptin's metabolic and immune functions can be uncoupled at the ligand/receptor interaction level. Cell Mol Life Sci. 2015 Feb;72(3):629-44.

40 Zabeau L, Wauman J, Dam J, Van Lint S, Burg E, De Geest J, et al. A novel leptin receptor antagonist uncouples leptin's metabolic and immune functions. Cell Mol Life Sci. 2019 Mar;76(6):1201-14.

41 Couturier C, Jockers R. Activation of the leptin receptor by a ligand-induced conformational change of constitutive receptor dimers. J Biol Chem. 2003 Jul;278(29):2660411.

42 Al-Massadi O, Quiñones M, Clasadonte J, Hernandez-Bautista R, Romero-Picó A, Folgueira $\mathrm{C}$, et al. MCH Regulates SIRT1/FoxO1 and Re- duces POMC Neuronal Activity to Induce Hyperphagia, Adiposity, and Glucose Intolerance. Diabetes. 2019 Dec;68(12):2210-22.

43 Peelman F, Couturier C, Dam J, Zabeau L, Tavernier J, Jockers R. Techniques: new pharmacological perspectives for the leptin receptor. Trends Pharmacol Sci. 2006 Apr;27(4): 218-25.

44 Wauman J, Zabeau L, Tavernier J. The Leptin Receptor Complex: Heavier Than Expected? Front Endocrinol (Lausanne). 2017 Feb;8:30.

45 Madadi G, Dalvi PS, Belsham DD. Regulation of brain insulin mRNA by glucose and glucagon-like peptide 1. Biochem Biophys Res Commun. 2008 Nov;376(4):694-9.

46 Roujeau C, Jockers R, Dam J. Endospanin 1 Determines the Balance of Leptin-Regulated Hypothalamic Functions. Neuroendocrinology. 2019;108(2):132-41.

47 Millucci L, Ghezzi L, Bernardini G, Santucci A. Conformations and biological activities of amyloid beta peptide 25-35. Curr Protein Pept Sci. 2010 Feb;11(1):54-67.

48 Ariga T, Kobayashi K, Hasegawa A, Kiso M, Ishida $\mathrm{H}$, Miyatake $\mathrm{T}$. Characterization of high-affinity binding between gangliosides and amyloid beta-protein. Arch Biochem Biophys. 2001 Apr;388(2):225-30.

49 Cecchi C, Nichino D, Zampagni M, Bernacchioni C, Evangelisti E, Pensalfini A, et al. A protective role for lipid raft cholesterol against amyloid-induced membrane damage in human neuroblastoma cells. Biochim Biophys Acta. 2009 Oct;1788(10):2204-16.

50 Evangelisti E, Cascella R, Becatti M, Marrazza G, Dobson CM, Chiti F, et al. Binding affinity of amyloid oligomers to cellular membranes is a generic indicator of cellular dysfunction in protein misfolding diseases. Sci Rep. 2016 Sep;6(1):32721.

51 Keppler A, Gendreizig S, Gronemeyer T, Pick $\mathrm{H}$, Vogel H, Johnsson K. A general method for the covalent labeling of fusion proteins with small molecules in vivo. Nat Biotechnol. 2003 Jan;21(1):86-9.

52 Vauthier V, Derviaux C, Douayry N, Roux T, Trinquet E, Jockers R, et al. Design and validation of a homogeneous time-resolved fluorescence-based leptin receptor binding assay. Anal Biochem. 2013 May;436(1):1-9.

53 Iserentant H, Peelman F, Defeau D, Vandekerckhove J, Zabeau L, Tavernier J. Mapping of the interface between leptin and the leptin receptor CRH2 domain. J Cell Sci. 2005 Jun; 118(Pt 11):2519-27.

54 Niv-Spector L, Gonen-Berger D, Gourdou I, Biener E, Gussakovsky EE, Benomar Y, et al. Identification of the hydrophobic strand in the A-B loop of leptin as major binding site III: implications for large-scale preparation of potent recombinant human and ovine leptin antagonists. Biochem J. 2005 Oct;391(Pt 2):221-30.

55 Peelman F, Van Beneden K, Zabeau L, Iserentant $\mathrm{H}$, Ulrichts $\mathrm{P}$, Defeau D, et al. Mapping of the leptin binding sites and design of a leptin antagonist. J Biol Chem. 2004 Sep; 279(39):41038-46.
56 Biener E, Charlier M, Ramanujan VK, Daniel N, Eisenberg A, Bjørbaek C, et al. Quantitative FRET imaging of leptin receptor oligomerization kinetics in single cells. Biol Cell. 2005 Dec;97(12):905-19.

57 Caron A, Dungan Lemko HM, Castorena CM, Fujikawa T, Lee S, Lord CC, et al. POMC neurons expressing leptin receptors coordinate metabolic responses to fasting via suppression of leptin levels. eLife. 2018 Mar;7:7.

58 Cowley MA, Smart JL, Rubinstein M, Cerdán MG, Diano S, Horvath TL, et al. Leptin activates anorexigenic POMC neurons through a neural network in the arcuate nucleus. $\mathrm{Na}$ ture. 2001 May;411(6836):480-4.

59 Secher A, Jelsing J, Baquero AF, HecksherSørensen J, Cowley MA, Dalbøge LS, et al. The arcuate nucleus mediates GLP-1 receptor agonist liraglutide-dependent weight loss. J Clin Invest. 2014 Oct;124(10):4473-88.

60 de la Monte SM. The Full Spectrum of Alzheimer's Disease Is Rooted in Metabolic Derangements That Drive Type 3 Diabetes. Adv Exp Med Biol. 2019;1128:45-83.

61 Kivipelto M, Ngandu T, Fratiglioni L, Viitanen M, Kåreholt I, Winblad B, et al. Obesity and vascular risk factors at midlife and the risk of dementia and Alzheimer disease. Arch Neurol. 2005 Oct;62(10):1556-60.

62 Whitmer RA, Gunderson EP, Quesenberry CP Jr, Zhou J, Yaffe K. Body mass index in midlife and risk of Alzheimer disease and vascular dementia. Curr Alzheimer Res. 2007 Apr;4(2):103-9.

63 Hassing LB, Dahl AK, Thorvaldsson V, Berg $S$, Gatz M, Pedersen NL, et al. Overweight in midlife and risk of dementia: a 40-year followup study. Int J Obes. 2009 Aug;33(8):893-8.

$64 \mathrm{Xu}$ WL, Atti AR, Gatz M, Pedersen NL, Johansson B, Fratiglioni L. Midlife overweight and obesity increase late-life dementia risk: a population-based twin study. Neurology. 2011 May;76(18):1568-74.

65 Crane PK, Walker R, Hubbard RA, Li G, Nathan DM, Zheng $\mathrm{H}$, et al. Glucose levels and risk of dementia. N Engl J Med. 2013 Aug; 369(6):540-8.

66 Uddin MS, Kabir MT, Al Mamun A, AbdelDaim MM, Barreto GE, Ashraf GM. APOE and Alzheimer's Disease: Evidence Mounts that Targeting APOE4 may Combat Alzheimer's Pathogenesis. Mol Neurobiol. 2019 Apr; 56(4):2450-65.

67 Ferreira LS, Fernandes CS, Vieira MN, De Felice FG. Insulin Resistance in Alzheimer's Disease. Front Neurosci. 2018 Nov; 12:830.

68 Serra-Batiste M, Ninot-Pedrosa M, Bayoumi M, Gairí M, Maglia G, Carulla N. A $\beta 42$ assembles into specific $\beta$-barrel pore-forming oligomers in membrane-mimicking environments. Proc Natl Acad Sci USA. 2016 Sep 113(39):10866-71.

69 Smith LM, Kostylev MA, Lee S, Strittmatter SM. Systematic and standardized comparison of reported amyloid- $\beta$ receptors for sufficien$c y$, affinity, and Alzheimer's disease relevance. J Biol Chem. 2019 Apr;294(15):6042-53. 
70 Degorce F, Card A, Soh S, Trinquet E, Knapik GP, Xie B. HTRF: A technology tailored for drug discovery - a review of theoretical aspects and recent applications. Curr Chem $\mathrm{Ge}-$ nomics. 2009 May;3(1):22-32.

71 Kang JH, Korecka M, Figurski MJ, Toledo JB, Blennow K, Zetterberg H, et al.; Alzheimer's Disease Neuroimaging Initiative. The Alzheimer's Disease Neuroimaging Initiative 2 Biomarker Core: A review of progress and plans. Alzheimers Dement. 2015 Jul;11(7): 772-91.

72 Cao Q, Shin WS, Chan H, Vuong CK, Dubois $\mathrm{B}, \mathrm{Li} \mathrm{B}$, et al. Inhibiting amyloid- $\beta$ cytotoxicity through its interaction with the cell surface receptor LilrB2 by structure-based design. Nat Chem. 2018 Dec;10(12):1213-21.

73 Shi XD, Sun K, Hu R, Liu XY, Hu QM, Sun $\mathrm{XY}$, et al. Blocking the Interaction between EphB2 and ADDLs by a Small Peptide Rescues Impaired Synaptic Plasticity and Memory Deficits in a Mouse Model of Alzheimer's Disease. J Neurosci. 2016 Nov;36(47):1195973.

74 Brooks AJ, Dai W, O’Mara ML, Abankwa D, Chhabra Y, Pelekanos RA, et al. Mechanism of activation of protein kinase JAK2 by the growth hormone receptor. Science. 2014 May;344(6185):1249783.

75 Langmead CJ. Determining allosteric modulator mechanism of action: integration of radioligand binding and functional assay data. Methods Mol Biol. 2011;746:195-209.

76 Changeux JP, Christopoulos A. Allosteric Modulation as a Unifying Mechanism for Receptor Function and Regulation. Cell. 2016 Aug;166(5):1084-102.

77 Williams KW, Elmquist JK. From neuroanatomy to behavior: central integration of peripheral signals regulating feeding behavior. Nat Neurosci. 2012 Oct;15(10):1350-5.
78 Hill JW, Williams KW, Ye C, Luo J, Balthasar $\mathrm{N}$, Coppari R, et al. Acute effects of leptin require PI3K signaling in hypothalamic proopiomelanocortin neurons in mice. J Clin Invest. 2008 May;118(5):1796-805.

79 Ishii M, Hiller AJ, Pham L, McGuire MJ, Iadecola C, Wang G. Amyloid-Beta Modulates Low-Threshold Activated Voltage-Gated L-Type Calcium Channels of Arcuate Neuropeptide Y Neurons Leading to Calcium Dysregulation and Hypothalamic Dysfunction. J Neurosci. 2019 Oct;39(44):8816-25.

80 Zheng H, Zhou Q, Du Y, Li C, Xu P, Lin L, et al. The hypothalamus as the primary brain region of metabolic abnormalities in APP/PS transgenic mouse model of Alzheimer's disease. Biochim Biophys Acta Mol Basis Dis. 2018 Jan;1864(1):263-73.

81 Sterniczuk R, Dyck RH, Laferla FM, Antle $\mathrm{MC}$. Characterization of the $3 \mathrm{xTg}-\mathrm{AD}$ mouse model of Alzheimer's disease: part 1. Circadian changes. Brain Res. 2010 Aug;1348:139-48.

82 Bates SH, Stearns WH, Dundon TA, Schuber M, Tso AW, Wang Y, et al. STAT3 signalling is required for leptin regulation of energy balance but not reproduction. Nature. $2003 \mathrm{Feb}$; 421(6925):856-9.

83 Bates SH, Kulkarni RN, Seifert M, Myers MG Jr. Roles for leptin receptor/STAT3-dependent and -independent signals in the regulation of glucose homeostasis. Cell Metab. 2005 Mar;1(3):169-78.

84 Coppari R, Ichinose M, Lee CE, Pullen AE, Kenny CD, McGovern RA, et al. The hypothalamic arcuate nucleus: a key site for mediating leptin's effects on glucose homeostasis and locomotor activity. Cell Metab. 2005 Jan;1(1):63-72.

85 Martin TL, Alquier T, Asakura K, Furukawa N, Preitner F, Kahn BB. Diet-induced obesity alters AMP kinase activity in hypothalamus and skeletal muscle. J Biol Chem. 2006 Jul; 281(28): 18933-41.

86 Ernst MB, Wunderlich CM, Hess S, Paehler M, Mesaros A, Koralov SB, et al. Enhanced Stat 3 activation in POMC neurons provokes negative feedback inhibition of leptin and insulin signaling in obesity. J Neurosci. 2009 Sep;29(37):11582-93.
87 Mainardi M, Spinelli M, Scala F, Mattera A, Fusco S, D'Ascenzo M, et al. Loss of LeptinInduced Modulation of Hippocampal Synaptic Trasmission and Signal Transduction in High-Fat Diet-Fed Mice. Front Cell Neurosci. 2017 Jul;11:225.

88 Davis JF, Choi DL, Schurdak JD, Fitzgerald MF, Clegg DJ, Lipton JW, et al. Leptin regulates energy balance and motivation through action at distinct neural circuits. Biol Psychiatry. 2011 Apr;69(7):668-74

89 McGregor G, Harvey J. Regulation of Hippocampal Synaptic Function by the Metabolic Hormone, Leptin: Implications for Health and Neurodegenerative Disease. Front Cell Neurosci. 2018 Oct;12:340.

90 Greco SJ, Bryan KJ, Sarkar S, Zhu X, Smith MA, Ashford JW, et al. Leptin reduces pathology and improves memory in a transgenic mouse model of Alzheimer's disease. J Alzheimers Dis. 2010;19(4):1155-67.

91 Doherty GH, Beccano-Kelly D, Yan SD, Gunn-Moore FJ, Harvey J. Leptin prevents hippocampal synaptic disruption and neuronal cell death induced by amyloid $\beta$. Neurobiol Aging. 2013 Jan;34(1):226-37.

92 Irving AJ, Harvey J. Leptin regulation of hippocampal synaptic function in health and disease. Philos Trans R Soc Lond B Biol Sci. 2013 Dec;369(1633):20130155.

93 Maletínská L, Popelová A, Železná B, Bencze $M$, Kuneš J. The impact of anorexigenic peptides in experimental models of Alzheimer's disease pathology. J Endocrinol. 2019 Feb; 240(2):R47-72.

94 Kilkenny C, Browne W, Cuthill IC, Emerson M, Altman DG; NC3Rs Reporting Guidelines Working Group. Animal research: reporting in vivo experiments: the ARRIVE guidelines. Br J Pharmacol. 2010 Aug;160(7):1577-9. 